\title{
Shrinkage Mechanisms of Alkali-Activated Slag
}

\author{
Hailong Ye*, Aleksandra Radlińska \\ Department of Civil and Environmental Engineering, The Pennsylvania State University, 3127 \\ Research Drive, State College, PA, 16801,United States \\ * Corresponding author. Email: huy131@psu.edu Phone: +001 484-260-4003
}

\begin{abstract}
In this work, the physical and chemical changes of alkali-activated slag (AAS) after a prolonged drying treatment under various relative humidity $(\mathrm{RH})$ conditions were studied. The results show that the shrinkage kinetics of AAS is strongly dependent on the $\mathrm{RH}$, but irrespective of the moisture loss. At high RH, AAS exhibits a pronounced viscous characteristic, which is likely due to the rearrangement and reorganization of calcium-alumina-silicate-hydrate (C-A-SH). Meantime, micropore closure, silicate polymerization, and new interlayer formation were observed during microstructure rearrangement, indicating a strong interaction between adjacent C-A-S-H particles. The large shrinkage in AAS may be attributed to the structural incorporation of alkali cations in C-A-S-H, which reduces the stacking regularity of C-A-S-H layers and makes the C-A-S-H easier to collapse and redistribute upon drying.
\end{abstract}

Keywords: Alkali-activated slag; Drying shrinkage; Shrinkage mechanism; Microstructural change; Calcium-alumina-silicate-hydrate 


\section{Introduction}

Alkali-activated slag (AAS) is an alternative cementitious binder with promising mechanical properties and excellent chemical durability $[1,2]$. In comparison to ordinary portland cement (OPC), AAS can significantly reduce the environmental impacts of concrete products by lowering $73 \%$ greenhouse gas emissions, $43 \%$ energy demand and $25 \%$ water use due to repurposing steel industry byproducts [3]. Despite its promising mechanical and eco-friendly performance, AAS has not received broader industry acceptance, primarily due to the uncertain long-term durability and insufficient durability against shrinkage and micro-cracking [4, 5], carbonation and corrosion [6], and potential alkali-aggregate reaction [7].

Many studies to date reported that AAS exhibits large autogenous and drying shrinkage, considerably higher than that of OPC $[4,5,8-10]$. For example, Cartwright et al. measured the autogenous and drying shrinkage of four distinctive AAS mortars with various types and dosages of activator. Their research documented that AAS has up to six times higher shrinkage, finer

pore structure, and lower stiffness than OPC [4]. Collins et al. attributed the high shrinkage of AAS to the higher capillary stress resulting from its pore size distribution being finer than that of OPC [8]. Similar experimental results and conclusions were also reported by other researchers [9, 
10]. However, the scientific and comprehensive reasoning behind the high drying shrinkage behavior of AAS is still unknown.

The objective of this study is to enable a thorough understanding of the mechanisms and causes

of large shrinkage in AAS from a microstructural viewpoint. An accurate explanation of shrinkage mechanisms in AAS is needed to provide the fundamentals leading to development of effective mitigating strategies against shrinkage and cracking in cementitious binders and in turn, will enhance the long-term durability of AAS.

\section{Experimental programs}

\subsection{Materials, mixing proportion and sample preparation}

A Grade 120 (ASTM C989M-12a) ground granulated blast-furnace slag with a specific gravity of 2.89 and a control Type I (ASTM C150) portland cement with a specific gravity of 3.14 were used in this work. The chemical composition of slag and cement are listed in Table 1. To prepare activator for AAS, sodium hydroxide $(\mathrm{NaOH})$ pellets was dissolved in distilled water and sealed in airtight containers to prevent carbonation and evaporation. The resulting activator was a $4 \mathrm{M}$ $\mathrm{NaOH}$ solution with a density of $1.09 \mathrm{~g} / \mathrm{cc}$ and $\mathrm{pH}$ of 14.60 .

$\mathrm{NaOH}$-activated slag and control OPC paste samples were studied. They were designed using a constant volumetric liquid (distilled water or activator) to solid (slag or cement) ratio of 1.30 , 
yielding an initial binder porosity of 56.5\%. Due to the different densities between slag and cement, as well as $\mathrm{NaOH}$ solution and water, the resulting liquid-to-solid mass ratio of prepared mixtures was 0.49 and 0.41 for AAS and OPC, respectively.

After mixing according to ASTM C305-12, a non-standardized mold was designed to cast "minibar" prism samples with a dimension of $12.7 \mathrm{~mm} \times 12.7 \mathrm{~mm} \times 139.7 \mathrm{~mm} \mathrm{(1/2}$ inch $\times 1 / 2$ inch $\times 51 \frac{1}{2}$ inches). The use of 'mini-bar' samples enabled the samples to reach equilibrium with environments in a much shorter time. The samples were further cured at moist room $(100 \% \mathrm{RH}$, $23 \pm 0.5^{\circ} \mathrm{C}$ ) for 24 hours before demolding.

Table 1 Chemical composition (by mass \%) of slag and portland cement

\begin{tabular}{cccccccccccccc}
\hline & $\mathrm{CaO}$ & $\mathrm{SiO}_{2}$ & $\mathrm{Al}_{2} \mathrm{O}_{3}$ & $\mathrm{MgO}$ & $\mathrm{SO}_{3}{ }^{\mathrm{a}}$ & $\mathrm{S}^{2-}$ & $\mathrm{Fe}_{2} \mathrm{O}_{3}$ & $\mathrm{Na}_{2} \mathrm{O}$ & $\mathrm{K}_{2} \mathrm{O}$ & $\mathrm{P}_{2} \mathrm{O}_{5}$ & $\mathrm{MnO}$ & $\mathrm{TiO}_{2}$ & $\mathrm{LOI}$ \\
\cline { 2 - 12 } Slag & 43.83 & 30.04 & 12.74 & 4.79 & 3.11 & 0.85 & 1.16 & 0.24 & 0.40 & 0.08 & 0.22 & - & 2.56 \\
Cement & 62.5 & 19.9 & 5.44 & 2.31 & 4.93 & - & 2.26 & 0.30 & 0.89 & 0.23 & 0.09 & 0.29 & 0.86
\end{tabular}

Note: a: The element compositions were measured by ICP-AES method, the relatively high $\mathrm{SO}_{3}$ content in this slag is primarily due to the presence of gypsum

\subsection{Measurements of length and weight changes}

After demolding, samples were placed in Vena VC-10 environmental chambers capable of creating environments with various $\mathrm{RH}$, temperature, and gaseous conditions and allowed to dry. In this study, the environmental chambers were programmed for four different RH (i.e. $70 \%$, 
$50 \%, 30 \%$, and $11 \%)$ and constant temperature $\left(23 \pm 0.5^{\circ} \mathrm{C}\right)$. To prevent potential carbonation in AAS during the experiments, dry nitrogen $\left(\mathrm{N}_{2}\right)$ was purged in chambers continuously and the concentration of $\mathrm{CO}_{2}$ was periodically checked with a portable $\mathrm{CO}_{2}$ analyzer to be consistently 0 ppm. To ensure reproducibility, at least three duplicate samples were prepared for AAS and OPC mixtures dried at each RH condition.

The changes in length and weight of AAS and OPC paste samples were recorded for up to 70 days. After 70 days of drying, the samples were immediately soaked in distilled water for two hours. Afterwards, the samples were taken out and the excess water at the surfaces of specimens was wiped off using dry paper towels, followed by the length and mass measurements. The length measurements were taken utilizing a modified digital comparator with an invar rod and a measuring accuracy of 0.0001 inch. Simultaneous mass measurements were taken using a high precision balance with an accuracy of $0.01 \mathrm{~g}$.

In addition, after AAS samples were dried at various RH for 70 and 140 days, they were further characterized by selected experimental techniques including scanning electron microscopy, nitrogen gas and water vapor sorption tests, X-ray diffraction, and ${ }^{29} \mathrm{Si}$ nuclear magnetic resonance (as summarized in Table 2). For most of the implemented experiments in Table.2, samples had to be dried prior to testing. In order to preserve the microstructure of AAS samples conditioned at various RH, the solvent-exchange method (i.e. immersion in isopropyl alcohol for two weeks and then vacuum drying for one week) was adopted. Previous investigation 
demonstrated that solvent-exchange method is the most gentle way to preserve the microstructural features in cementitious materials [11]. To ensure reproducibility, duplicate measurements were performed on specimens selectively for most of the material characterization techniques.

Table 2 Summary of the experimental program for characterization of AAS dried at various RH Experiments Drying duration and relative humidity $(\% \mathrm{RH})$

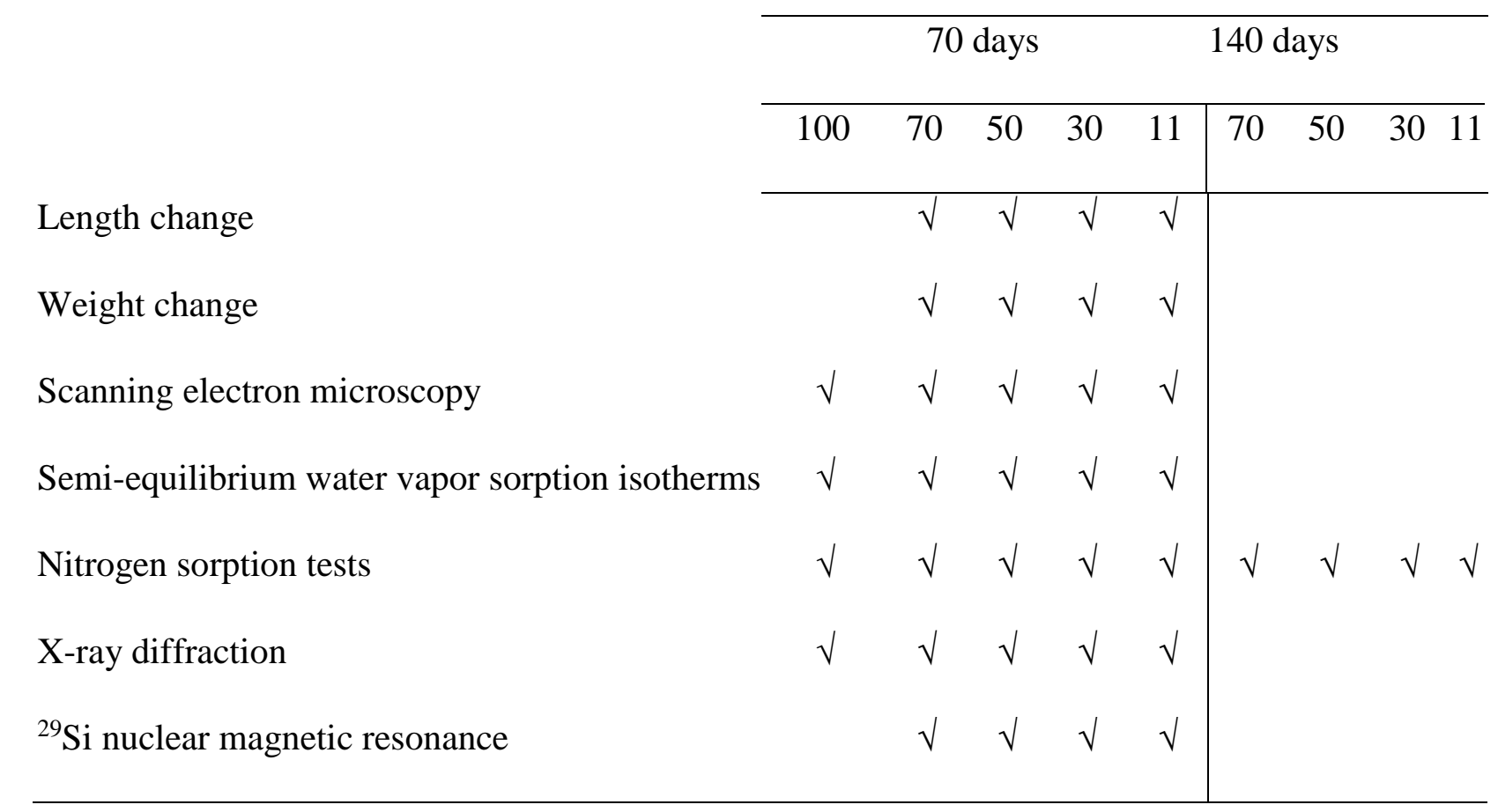

2.3 Scanning electron microscopy (SEM) 
Scanning electron microscopy with a backscattered electron (BSE) detector was utilized to image hardened AAS pastes dried at various RH. This allowed investigating the influence of RH on the microstructure characteristics (e.g. degree of hydration) of AAS. After solvent-vacuum drying, the samples were epoxy impregnated, surface polished, and carbon-coated.

To quantify the degree of hydration in AAS, quantitative SEM image analysis (SEM-IA) was implemented in this work. The principle of this method is based on sensitivity of BSE to the chemical composition of the analyzed materials, which leads to contrast in the grey level histogram [12]. Considering that slag is denser than the hydrated phases, therefore it appears brighter in the BSE images, as further explained in Section 3.2. The measurement uncertainty mainly originates from the threshold and the edge detection. The BSE-SEM images were converted to binary images through a series of image processing techniques to obtain the area fraction of unhydrated slag. Therefore, the degree of hydration was estimated according to the calculated area fraction of unhydrated slag and the initial volume fraction of raw slag in the mixing proportions (mentioned in Section 2.1). In the present study, eleven BSE images captured at different locations with a magnification of 500x were used to perform SEM-IA for each sample.

\subsection{Semi-equilibrium water vapor sorption (SEWVS) isotherms}

After solvent-vacuum dried, small (5-10 mg) slices of AAS samples were placed in a plastic dish which was kept in varying RH (nitrogen purged). The AAS samples were subsequently 
equilibrated in the Vena VC-10 environmental chambers to $1 \%, 5 \%, 11 \%, 20 \%, 30 \%, 40 \%, 50 \%$, $60 \%, 70 \%, 80 \%, 90 \%, 99 \% \mathrm{RH}$, and circled back to $5 \%$. Since the samples were very small, they reached equilibrium quickly and their mass was measured in one week time intervals. Therefore, the degree of saturation, $S_{R H}$, at each equilibrated $\mathrm{RH}$ can be obtained using the following equations:

$$
S_{R H}=\frac{W_{R H}-W_{1 \%}}{W_{99 \%}-W_{1 \%}}
$$

Where $W_{R H}$ is the weight of samples at an arbitrary RH.

\subsection{Nitrogen sorption tests}

Nitrogen sorption analysis was conducted using an ASAP 2020 Automated Surface Area and Porosimetry System (Micromeritics) at a temperature of $77.350 \mathrm{~K}$. The samples were solventvacuum dried prior to degassing. The specific surface areas were calculated from the adsorption branch by the Brunauer, Emmett and Teller (BET) method [13].

\subsection{X-ray diffraction $(X R D)$}

Before XRD test, AAS paste samples were crushed and solvent-vacuum dried before milling to fine size powders. The powers were further filled into a zero-background plate using front-fill method. XRD data was collected using a PANalytical Empyrean diffractometer in a conventional Bragg-Brentano $\theta-2 \theta$ configuration. $\mathrm{CuK} \alpha \mathrm{X}$-ray $(\lambda=1.5418 \AA)$ was generated using $40 \mathrm{~mA}$ and 
$45 \mathrm{kV}$ operating conditions. A beta-filter Nickle was used to remove the $\beta$ diffraction spectrums. Incident beam Soller slits of $0.04^{\circ}$ were used, and the incident divergence and anti-scatter slits were fixed at $0.25^{\circ}$ and $0.5^{\circ}$, respectively. An anti-scatter slit was fixed at $0.25^{\circ}$ and the Soller slits limiting the axial divergence to 0.04 radians were positioned in the diffracted beam path. The AAS samples were scanned continuously between $5^{\circ}$ and $45^{\circ} 2 \theta$ under these conditions.

$2 .{ }^{29}$ Si solid-state nuclear magnetic resonance (NMR)

Solvent-vacuum dried AAS powders were used for ${ }^{29} \mathrm{Si}$ NMR tests. The ${ }^{29} \mathrm{Si}$ NMR spectra were recorded on a Bruker AV-300 spectrometer (9.39 T magnetic field) at $5.0 \mathrm{kHz}$ spinning rate in 4mm zirconium MAS rotor. The ${ }^{29} \mathrm{Si}$ chemical shift was referenced relative to tetramethylsilane $\mathrm{Si}\left(\mathrm{CH}_{3}\right)_{4}$ (TMS) at $0 \mathrm{ppm}$. The ${ }^{29} \mathrm{Si}$ NMR spectrums were deconvoluted using commercial software MestReNova.

\section{Results}

3.1 Length and mass changes

Figure 1 shows the time-dependent length and mass changes of AAS and OPC pastes at various RH. It can be seen that AAS has a considerably higher shrinkage and moisture loss than OPC, regardless of RH they were exposed to. Additionally, OPC samples demonstrate a higher shrinkage when dried at a lower $\mathrm{RH}$, as previously reported $[14,15]$. However, AAS exhibits 
higher shrinkage magnitude when exposed to higher RH (e.g. drying at 70\% RH results in larger shrinkage than drying at $11 \% \mathrm{RH}$ ). It also shows that the shrinkage magnitude of AAS is gradually increased when exposed to $70 \%$ and $50 \% \mathrm{RH}$, but almost constant after drying at $30 \%$ and $11 \% \mathrm{RH}$ for about 20 days. This distinct drying shrinkage characteristic of AAS in comparison to OPC has been reported by the authors before [5], but mechanisms accounting for this behavior will be explained in this study. In addition, at the same RH, AAS loses moisture more slowly than OPC, although the difference is marginal.

Figure 2 shows the kinetics of shrinkage for AAS and OPC pastes at various RH. It can be seen that OPC exhibits the highest shrinkage rate after being exposed to drying for 3 days, irrespective of the RH conditions. However, the appearance of the highest shrinkage rate for AAS system depends on the RH and tends to be delayed for samples dried at higher RH. For instance, the highest shrinkage rate for AAS exposed to $70 \% \mathrm{RH}$ occurs after drying for 28 days, while it occurs at 11 days for AAS exposed to $11 \%$ RH. It indicates that the shrinkage development of AAS shows viscous characteristics and its kinetics is highly $\mathrm{RH}$-dependent.

Figure 3 shows the correlation between shrinkage and moisture loss for both OPC and AAS pastes. For OPC, there exists a strong correlation between drying shrinkage and moisture loss, which is consistent with the finding reported in the literature [15]. However, the correlation between shrinkage and moisture loss in AAS does not follow the same trend. It shows that for AAS, the shrinkage can dramatically increase despite the moisture loss being almost constant. In 
other words, the slope of shrinkage development with respect to moisture loss in AAS is much steeper than that of OPC. It indicates that the pronounced viscous characteristic is not due to the gradual loss of moisture, but more likely due to the microstructural rearrangement.

When directly soaked in the water for a period of short time (i.e. two hours), OPC absorbs most of the lost water back while half of the drying shrinkage is irreversible. However, AAS can only partially re-saturate its pore structure and majority of the shrinkage is irreversible (approximately 60\%-99\%), especially for samples dried at high RH (e.g. 70\% and 50\% RH). It should be noted here that AAS samples disintegrated after soaking in water for about two hours, while OPC samples remained intact.

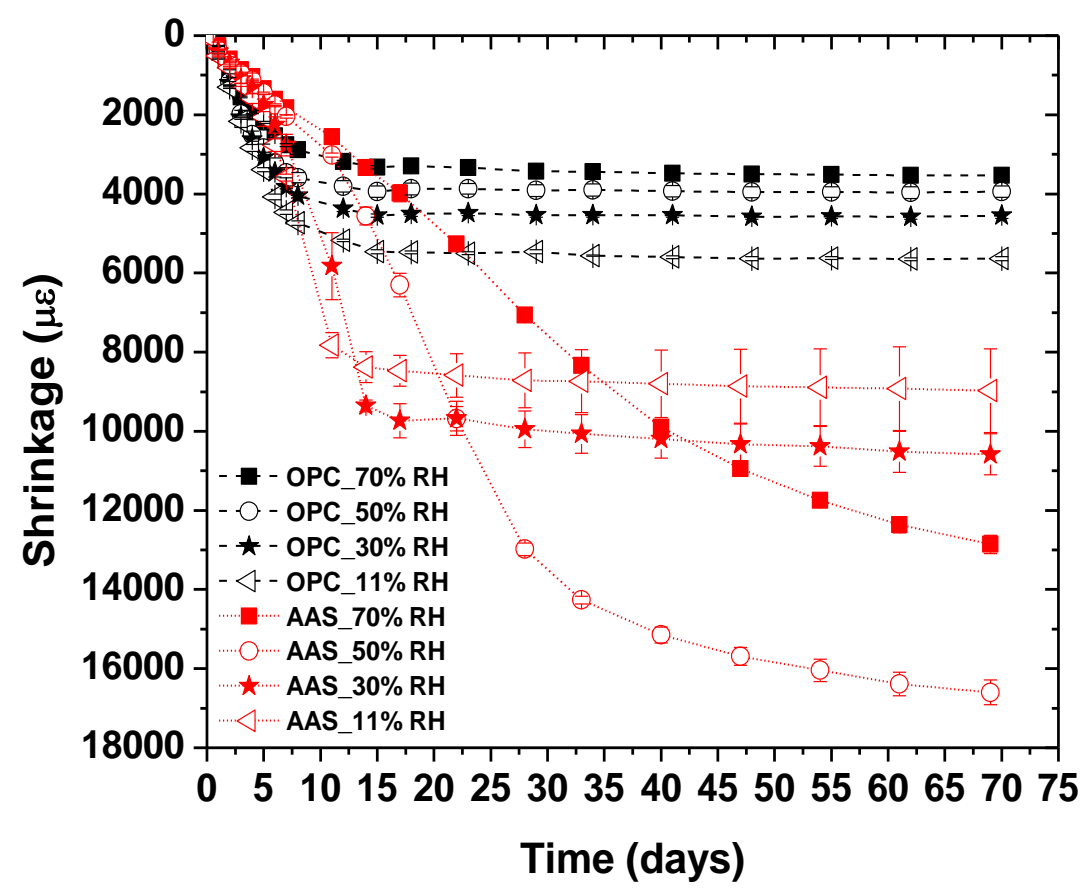


(a)

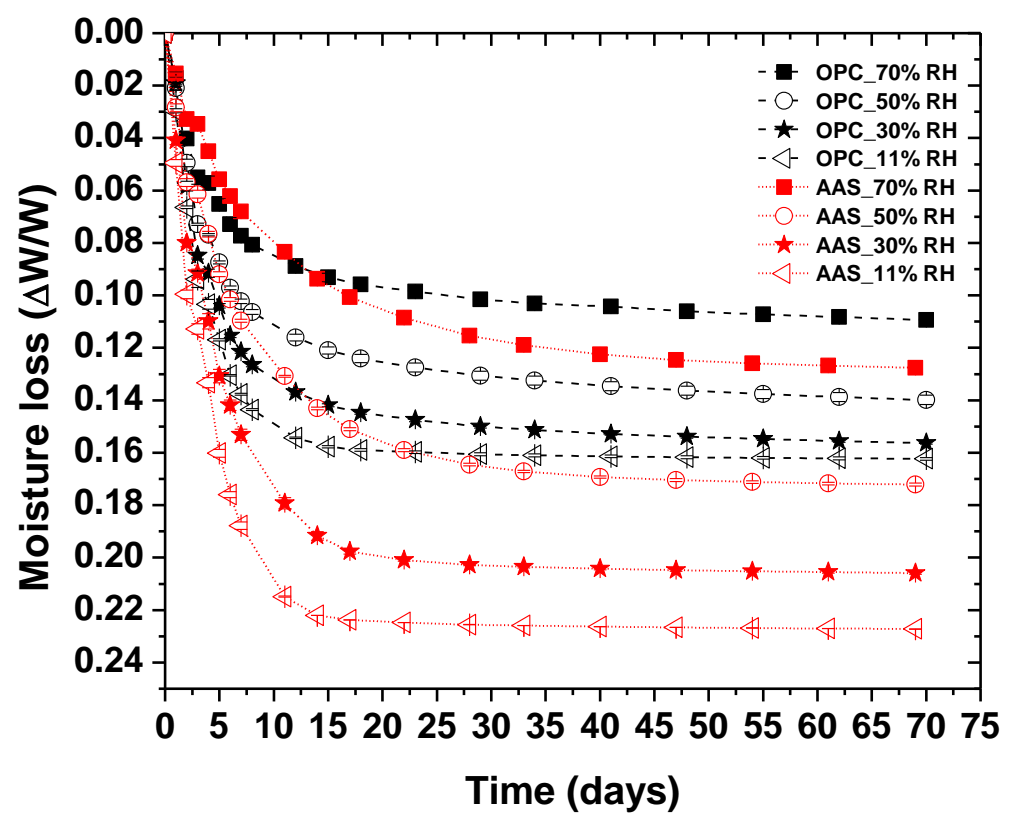

(b)

Figure 1 Time-dependent shrinkage and moisture loss for OPC and AAS exposed to various RH (Error bars represent the standard deviations) (a) Shrinkage; (b) Moisture loss 


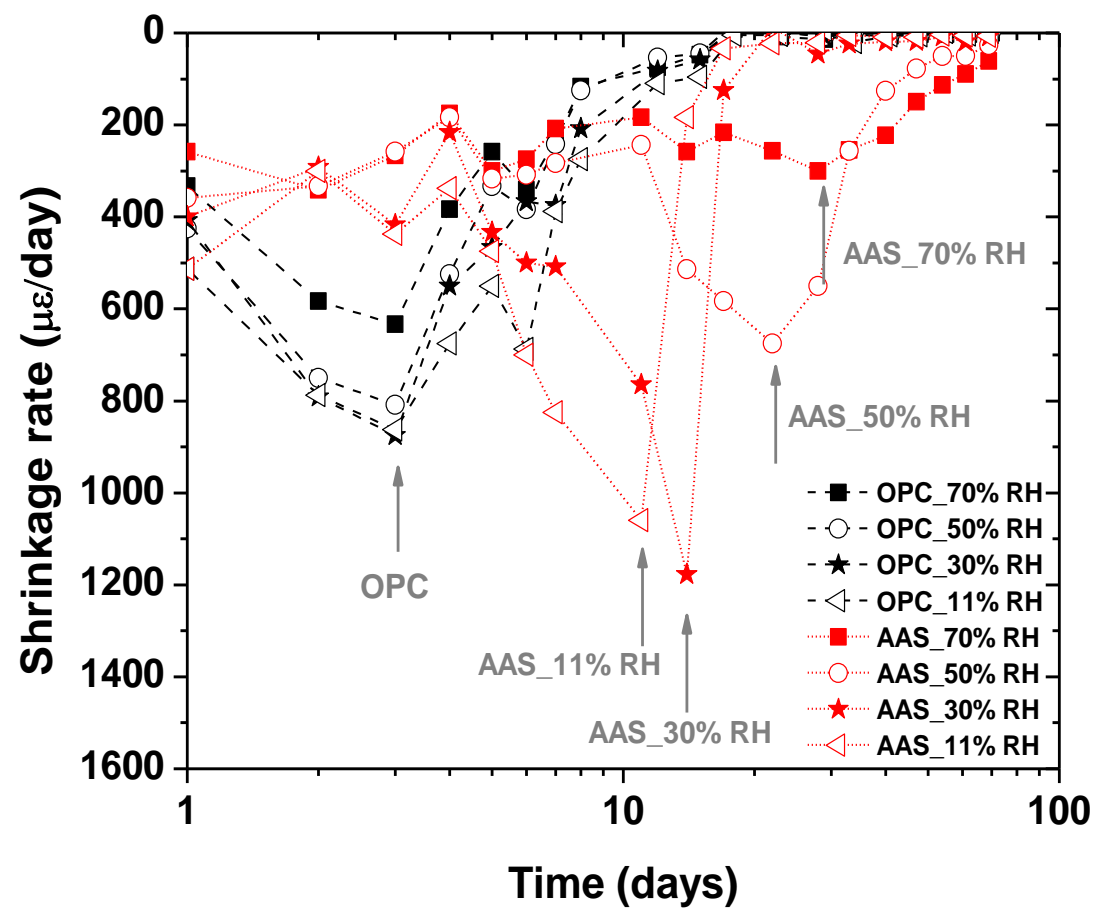

Figure 2 Kinetics of shrinkage for OPC and AAS exposed to various RH 


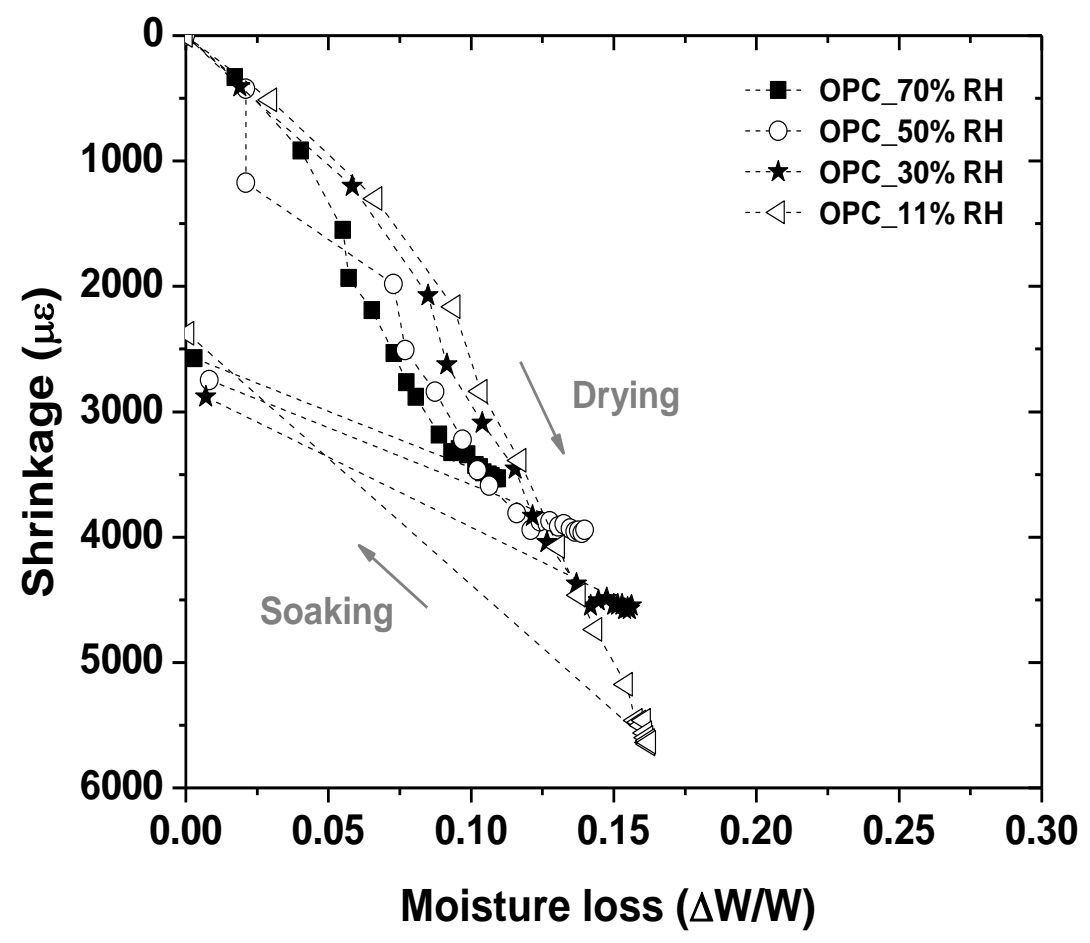

(a) OPC

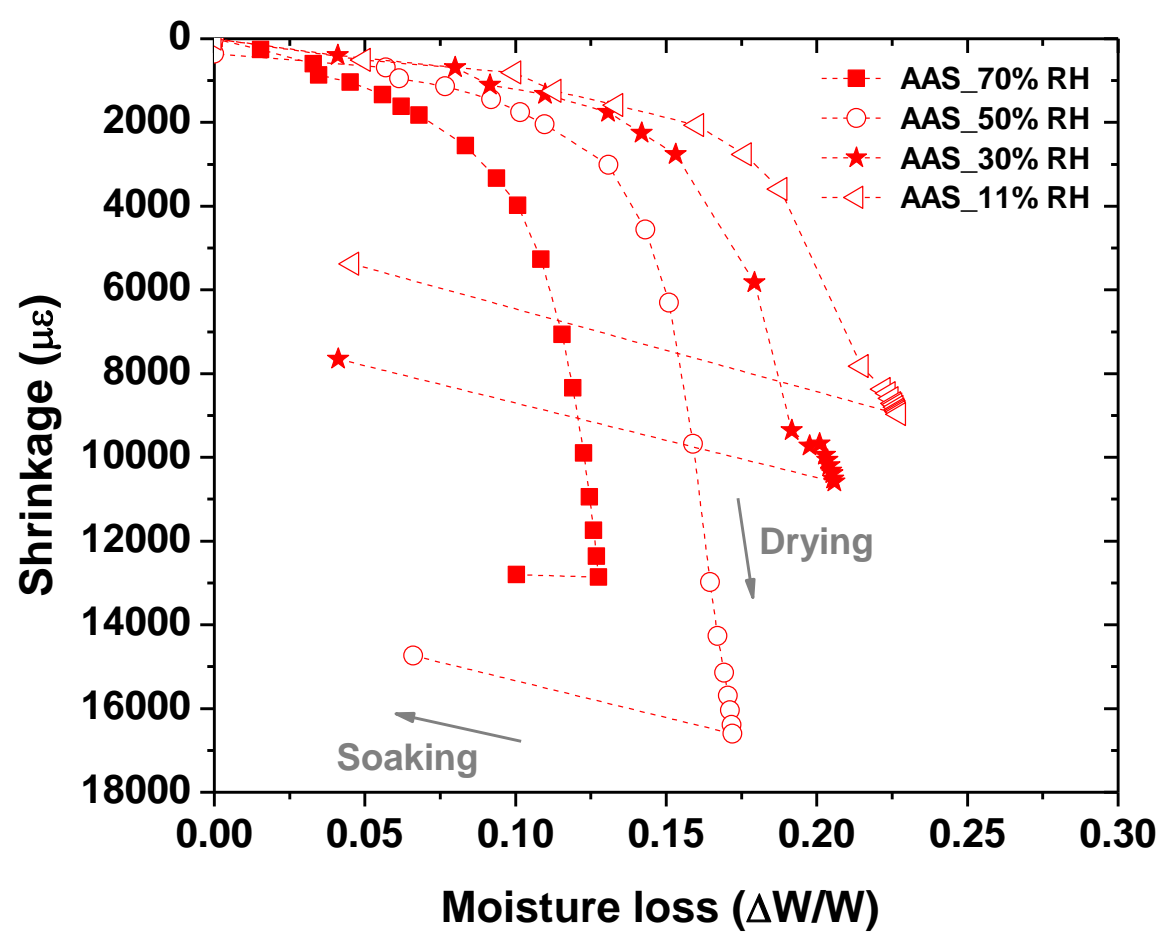




\section{(b) AAS}

Figure 3 Length change versus moisture loss (a) OPC; (b) AAS

\subsection{Microstructure}

Figure 4 shows the BSE-SEM images of AAS dried at various RH. The bright, unhydrated slag particles are all surrounded by grey hydration products, containing calcium-alumina-silicatehydrate (C-A-S-H) and other fiber-like hydrated phases [16, 17]. The estimated degree of hydration for AAS decreases for samples exposed to lower RH, showing that the slag hydration is strongly dependent on the RH. The drying shrinkage of the hydration products of AAS (see Table 3) can be approximated using a two-phase composite model [18] in which AAS paste contains nonshrinking unhydrated slag and hydrated products. It can be seen that the highest shrinkage of hydration products occurred at 50\% $\mathrm{RH}$, however the difference among AAS dried at $70 \%, 30 \%$, and $11 \% \mathrm{RH}$ is marginal. While this phenomenon does not indicate that the equilibrated shrinkage of the hydration products in AAS is irrespective of the drying RH, it indicates that the kinetics of shrinkage in AAS is strongly dependent on the experienced RH. 


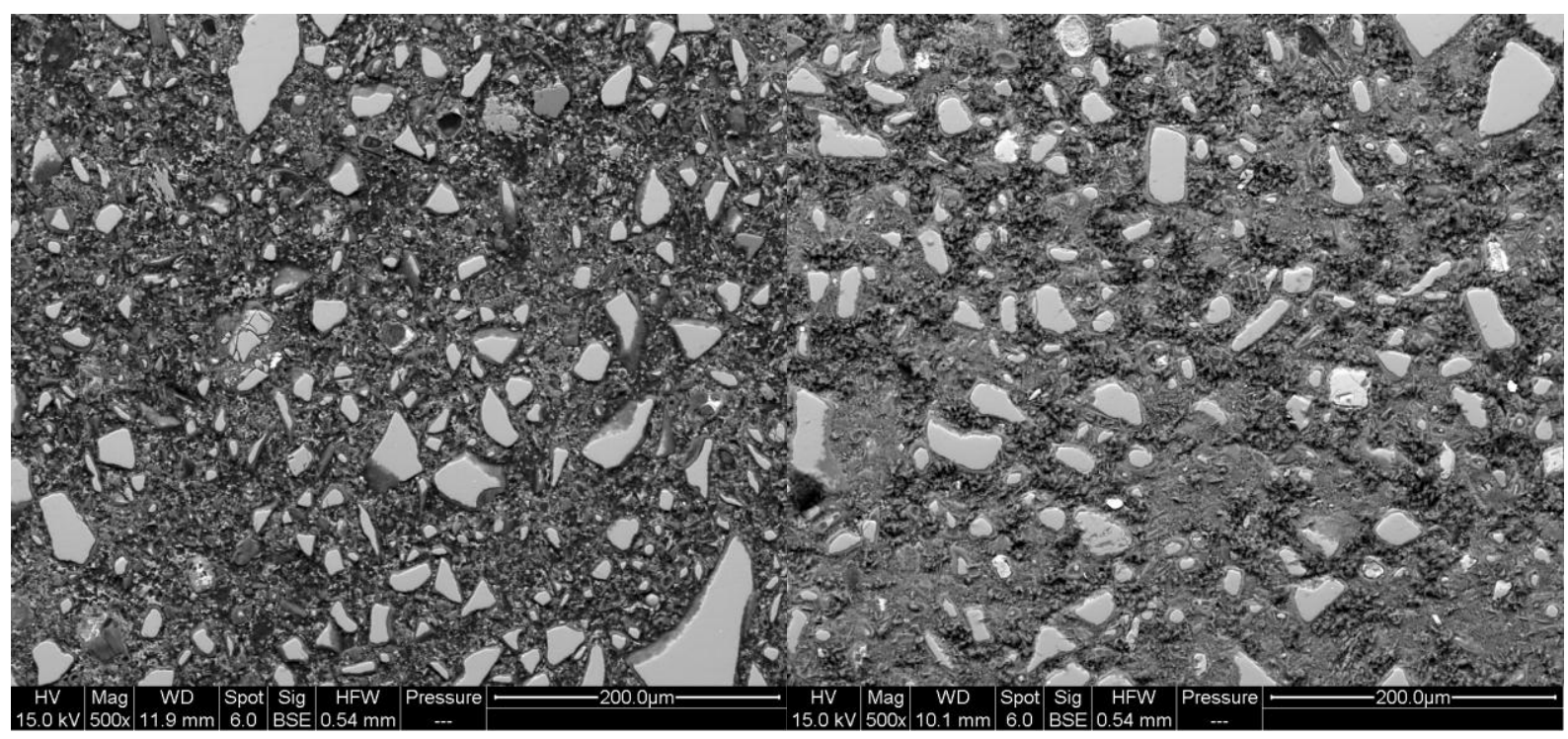

(a)

(b)

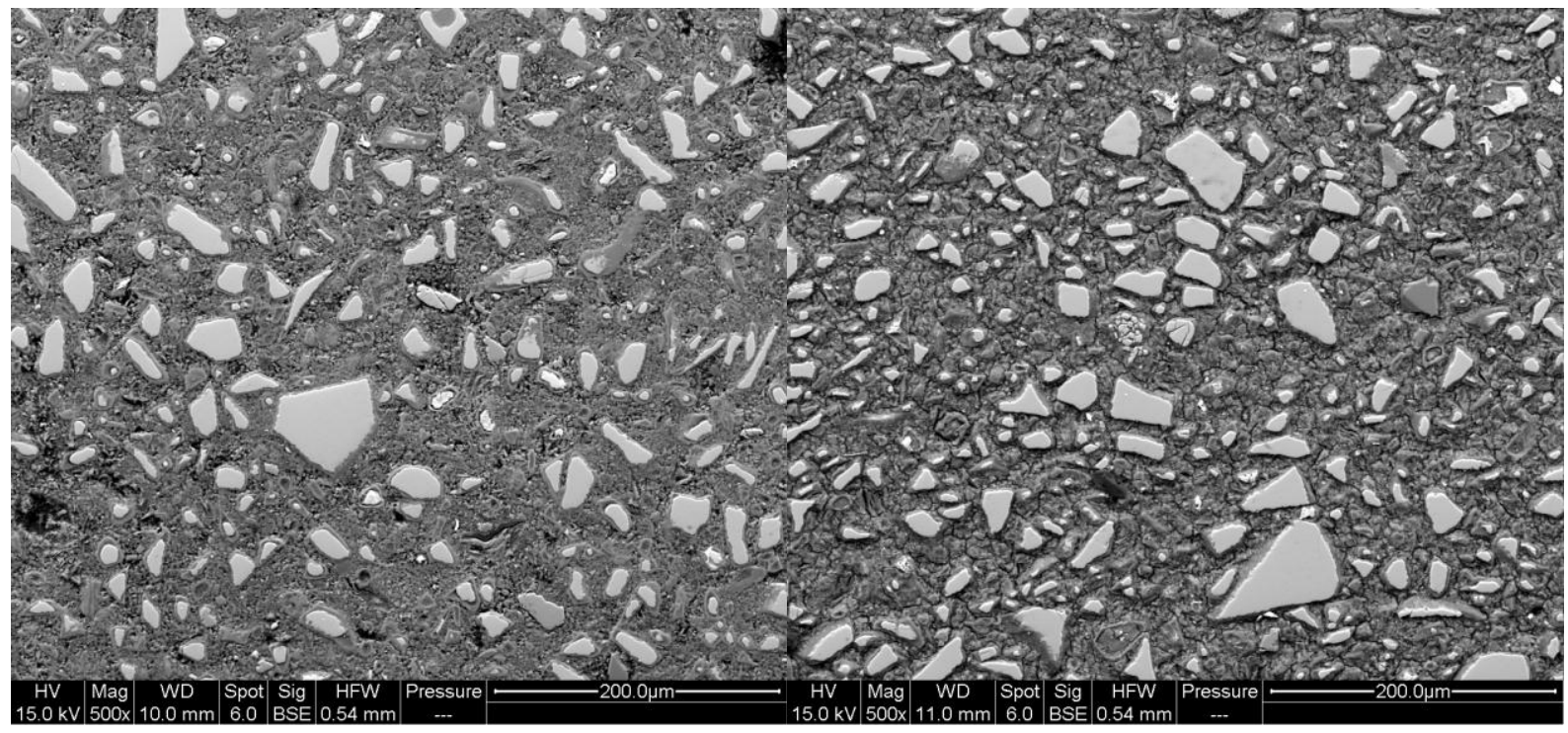

(c)

(d) 


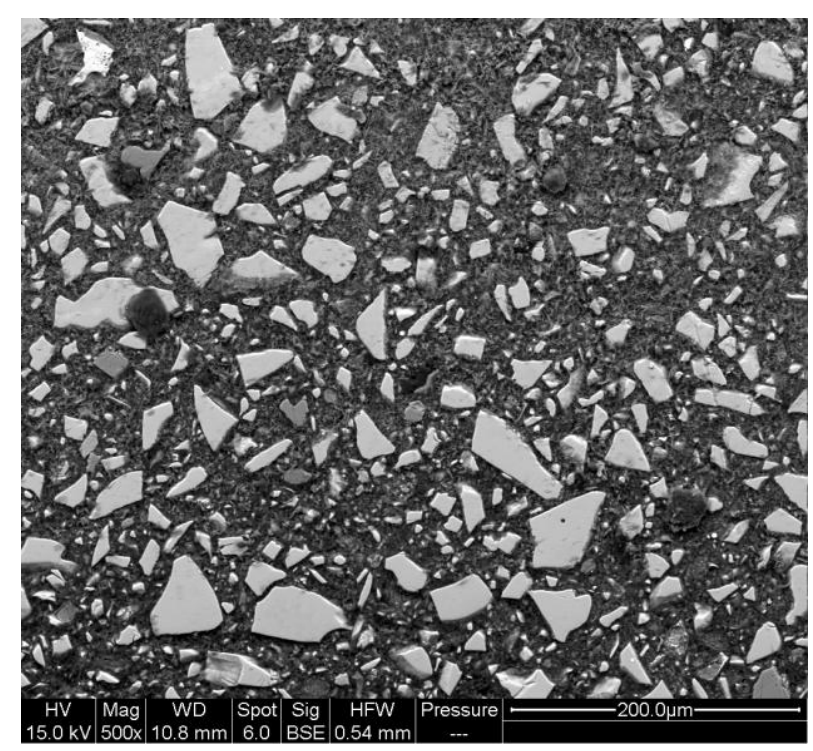

(e)

Figure 4 SEM images of AAS conditioned at various RH for 70 days (a) 100\%RH; (b) $70 \%$ RH; (c) $50 \%$ RH; (d)30\%RH; (e)11\%RH

Table 3 Shrinkage of AAS pastes and the hydration products dried at various $\mathrm{RH}$ for 70 days

\begin{tabular}{cccc}
\hline $\begin{array}{c}\text { Drying } \\
\text { RH }\end{array}$ & $\begin{array}{c}\text { Average shrinkage of } \\
\text { AAS pastes at } 70 \text { days } \\
(\mu \varepsilon)\end{array}$ & $\begin{array}{c}\text { Average degree of } \\
\text { hydration }^{\mathrm{a}} \text { at } 70 \text { days }\end{array}$ & $\begin{array}{c}\text { Approximated average } \\
\text { shrinkage of hydration }\end{array}$ \\
\hline $70 \% \mathrm{RH}$ & 12858 & $(\%)$ & 17633 \\
$50 \% \mathrm{RH}$ & 16600 & 64.0 & 23573 \\
$30 \% \mathrm{RH}$ & 10583 & 60.1 & 15593 \\
$11 \% \mathrm{RH}$ & 8975 & 56.0 & 14314 \\
\hline
\end{tabular}

Note: $\quad$ a: The standard derivation for degree of hydration is from $2.2 \%$ to $3.1 \%$. 
b: The shrinkage of hydration products in AAS is approximately estimated by adopting a twophase composite model proposed by Hobbs [18].

\subsection{Pore structure characterization}

Figure 5 shows the normalized nitrogen sorption isotherms for AAS dried at various relative pressures $\left(P / P_{0}\right)$, with normalization being operated by assigning the measured quantity adsorbed at $P / P_{0} \approx 1$ as $100 \%$. All curves show a type $\mathrm{V}$ classification according to International Union of Pure and Applied Chemistry system [19]. It indicates that AAS shows a hysteresis loop and has micropores and mesopores with an inflection point at a fairly high RH [20, 21]. In addition, AAS dried at various RH shows different shapes of isotherm curves than that of AAS cured in moist room, implying the pore structure modification due to drying. During adsorption, the nitrogen molecules condense in the order of increasing pore size [20]. It can be seen that in the adsorption branch, the AAS dried at various RH tends to adsorb a larger quantity of adsorbents than that of AAS conditioned at $100 \% \mathrm{RH}$. It may suggest that the pore structure of AAS becomes more refined as a result of drying. During desorption, nitrogen becomes thermodynamically unstable with respect to the vapor phase in the order of decreasing pore size [20]. However, due to the pore blocking effects (i.e. ink-bottle effects) [22], the large ink-bottle pores cannot empty through the smaller pore entrances until a low $P / P_{0}$ is reached [20]. At such, an improved hysteresis may imply more narrow necks in the pore networks. It can be seen that AAS dried at various RH seems to have a larger quantity of entrapped adsorbents and to show a higher extent of hysteresis compared with that conditioned at $100 \% \mathrm{RH}$, especially when $P / P_{0}$ ranges between 
0.45-0.85. This phenomenon is magnified for AAS dried at 70\% RH, implying the pore refining is enhanced at high RH.

Figure 6 shows the evolution of degree of saturation $S_{R H}$ as a function of RH for AAS dried at various RH calculated from SEWVS isotherms. It can be seen that hysteresis preserves over the whole range of RH for all samples, but magnifies for dried samples (especially for AAS dried at $70 \% \mathrm{RH})$. This finding agrees with the results obtained by nitrogen sorption test and indicates that drying results in pore structure refinement in AAS. It should be noted here that due to the difference in radius between nitrogen and water molecules, they are able to penetrate in different ranges of pore spaces at the low temperatures applied in these experiments. Typically, some nitrogen molecules inaccessible regions are however accessible by water molecules [23, 24].

The BET-surface area for AAS dried at $70 \% \mathrm{RH}$ is noticeably reduced for samples at the age of 140 days, as compared to samples at 70 days (see Table 4), since the shrinkage has not reached equilibrium at 70 days yet. It indicates that drying promotes the closure of micro-pore in AAS over time, and creates some $\mathrm{N}_{2}$-inaccessible regions. In addition, it can be seen that the BETsurface area for hydration products of AAS increases with the decreasing RH at 70 days, which suggests that the pore collapse magnifies when drying at high RH. These phenomena will be explained in the Section 4.1. 


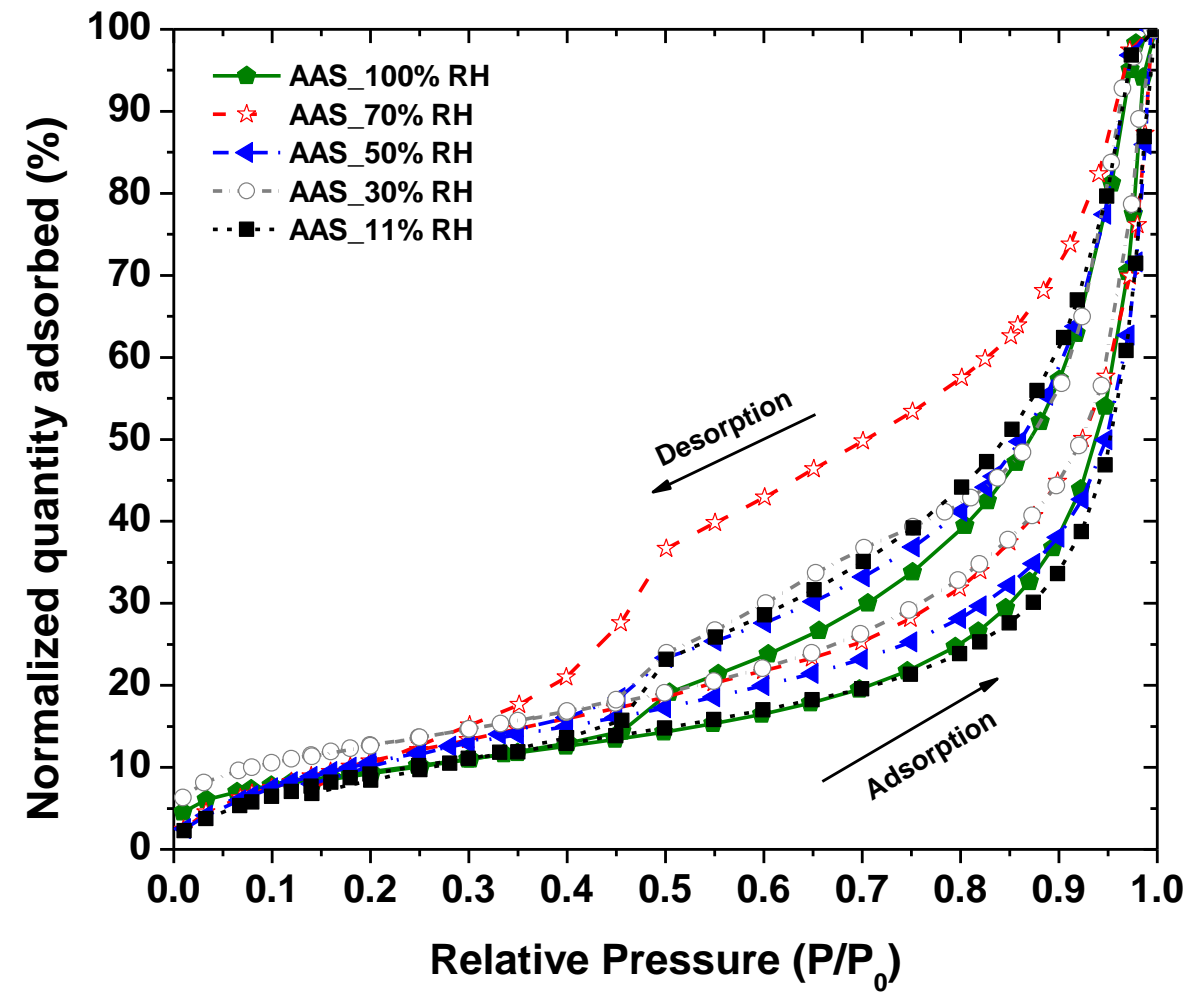

Figure 5 Nitrogen sorption isotherm curves for AAS samples dried at various RH, with normalization being operated by assigning the measured quantity adsorbed at $P / P_{0} \approx 1$ as $100 \%$ 


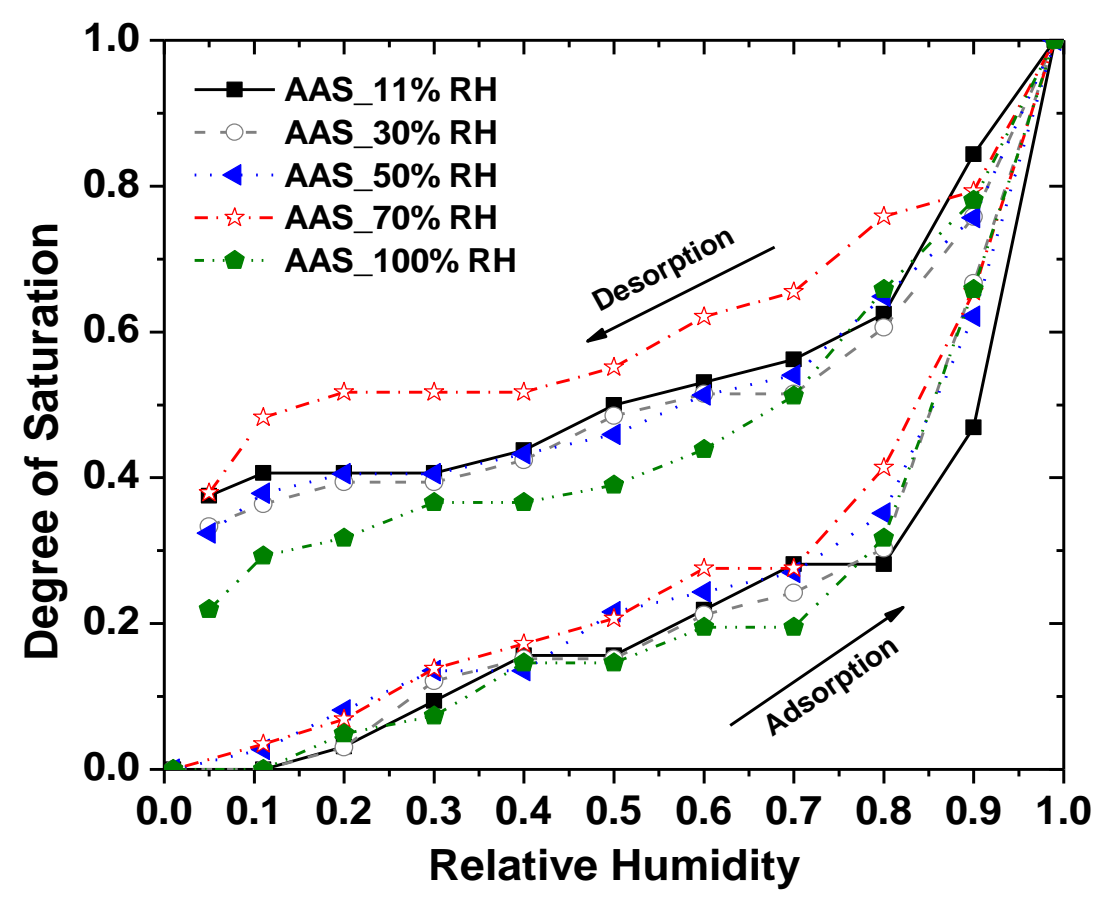

Figure 6 Semi-equilibrium water sorption isotherm curves for AAS samples dried at various $\mathrm{RH}$

Table 4 BET-surface areas of AAS and Al/Si ratio and mean chain length of C-A-S-H

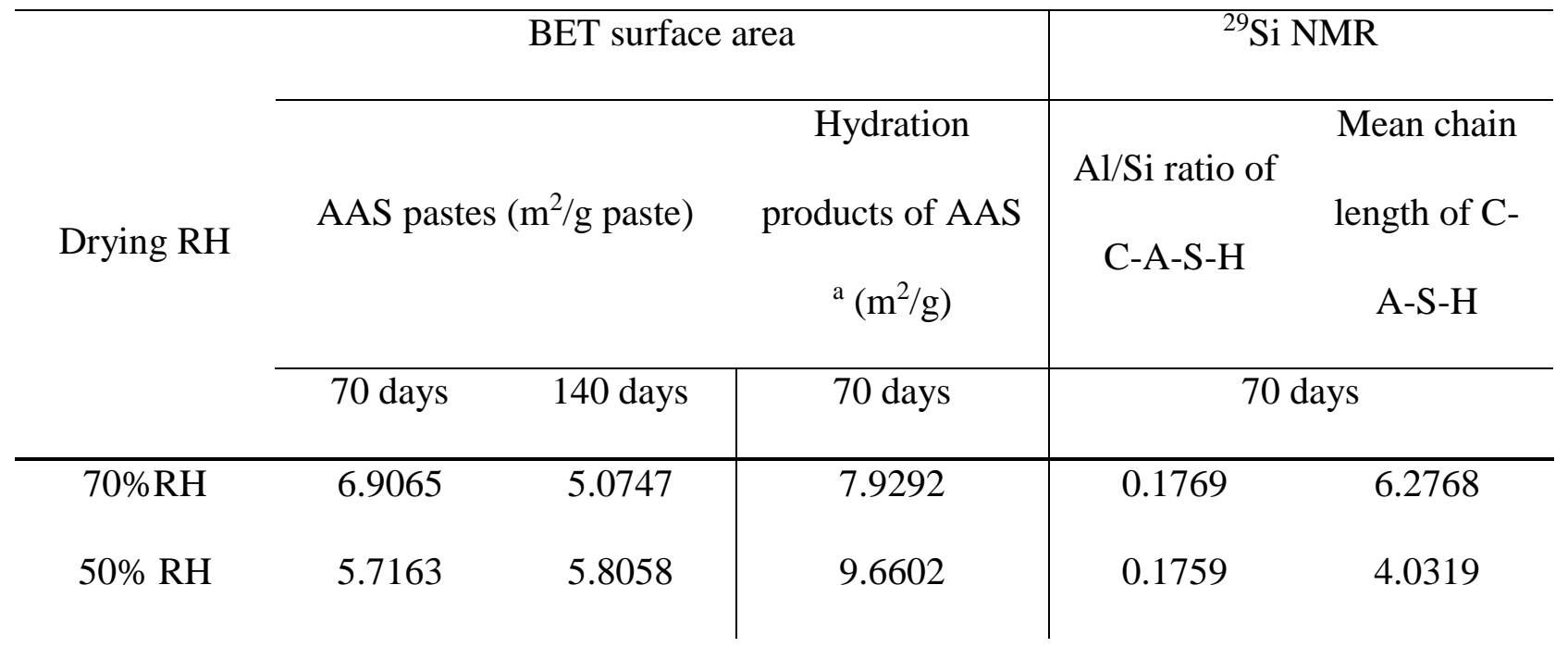




\begin{tabular}{rrr|r|rr}
$30 \%$ RH & 5.6106 & 5.6631 & 10.1127 & 0.1768 & 4.4108 \\
$11 \%$ RH & 5.7607 & 5.7802 & 12.2203 & 0.1783 & 4.3620 \\
\hline
\end{tabular}

Note: a: They were calculated by assuming 100\% slag hydration based on the value of degree of hydration shown in Table 3

\subsection{C-A-S-H nanostructure}

Figure 7 shows the XRD pattern for raw slag and AAS dried at various RH. The raw slag contains primarily amorphous structure with traces of crystalline gypsum (light grey solid lines) and monoclinic alite (light grey dash lines). The broad and diffuse peak in the range $2 \theta=30^{\circ}$ to $31.6^{\circ}$ is the result of the short range order of the $\mathrm{CaO}-\mathrm{SiO}_{2}-\mathrm{Al}_{2} \mathrm{O}_{3}-\mathrm{MgO}$ glass structure from unhydrated slag [7]. Consistently with previous research [16, 25, 26], the main hydration products in AAS are identified as C-S-H (I), hydrotalcite-type phases, and portlandite. In addition, aragonite and calcite are detected in AAS due to slight carbonation during mixing, sample preparation, or measurements. It can be seen drying at various RH can result in different XRD patterns in AAS. An extensive drying at $11 \% \mathrm{RH}$ causes a decrease in the interlayer thickness, indicating the loss of interlayer water in C-A-S-H. In addition, for AAS dried at $70 \% \mathrm{RH}$, there is a considerable increase in peak intensity (mass fraction) corresponding to C-S$\mathrm{H}$ (I), while other peak intensities keep almost unaltered, in comparison to that dried at other RH less than $100 \%$. 
Figures 8, 9 show the deconvoluted ${ }^{29} \mathrm{Si}$ solid-state NMR patterns of raw slag and AAS dried at various $\mathrm{RH}$. The chemical shift are normally interpreted in terms of the different silicon $\mathrm{Q}^{\mathrm{n}}$ environments, where $\mathrm{n}$ denotes the number of bridging oxygen linked to other Si atoms for each $\mathrm{Q}\left(\mathrm{SiO}_{4}\right)$ tetrahedral unit. Figure 10 shows the range of chemical shift corresponding to $\mathrm{Q}^{\mathrm{n}}$ unit in silicates and $\mathrm{Q}^{\mathrm{n}}(1 \mathrm{Al})$ unit in aluminosilicate, which were adopted by the present study for fitting the NMR spectrum of AAS [27]. It can be seen that raw slag is comprised of mainly $\mathrm{Q}^{0}$ and $\mathrm{Q}^{1}$, while $\mathrm{C}-\mathrm{A}-\mathrm{S}-\mathrm{H}$ gel contains primarily $\mathrm{Q}^{1}, \mathrm{Q}^{2}(1 \mathrm{Al})$, and $\mathrm{Q}^{2}$ [25]. The finding supports that the $\mathrm{Al}$ can incorporate into the dreierketten silicate chains of $\mathrm{C}-\mathrm{A}-\mathrm{S}-\mathrm{H}[28,29]$, while it does not drastically change the nature of the layered structure in $\mathrm{C}-\mathrm{A}-\mathrm{S}-\mathrm{H}$ as evidenced in XRD.

According to the previous research, the mean chain length (MCL) and Al/Si ratio in the C-A-S-H gel can be calculated using [30, 31]:

$$
\begin{gathered}
\mathrm{MCL}=\frac{2\left(\mathrm{Q}^{1}+\mathrm{Q}^{2}+1.5 \mathrm{Q}^{2}(1 \mathrm{Al})\right)}{\mathrm{Q}^{1}} \\
\mathrm{Al} / \mathrm{Si}=\frac{0.5 \mathrm{Q}^{2}(1 \mathrm{Al})}{\mathrm{Q}^{1}+\mathrm{Q}^{2}+\mathrm{Q}^{2}(1 \mathrm{Al})}
\end{gathered}
$$

The evolutions of MCL and Al/Si in the C-A-S-H as a function of drying RH (as shown in Table 4) indicates that the $\mathrm{Al} / \mathrm{Si}$ ratio almost keeps constant while a noticeable increase in MCL occurs in AAS dried at $70 \% \mathrm{RH}$. The enlargement of MCL in C-A-S-H gel indicates that there is a $\mathrm{Si}$ polymerization between adjacent C-A-S-H particles taking place during drying at $70 \% \mathrm{RH}$. 


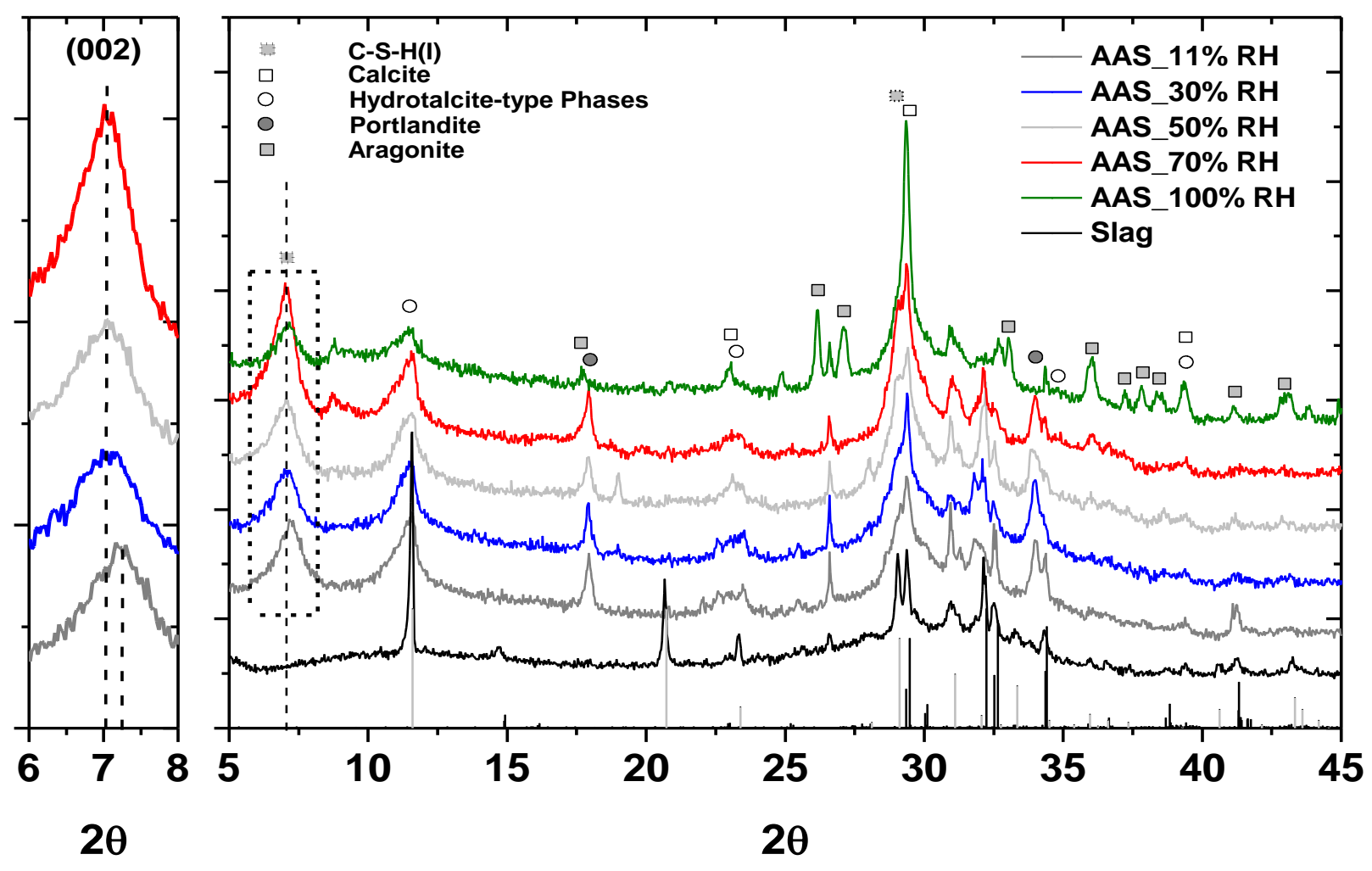

Figure 7 XRD patterns of raw slag and AAS dried at various RH 


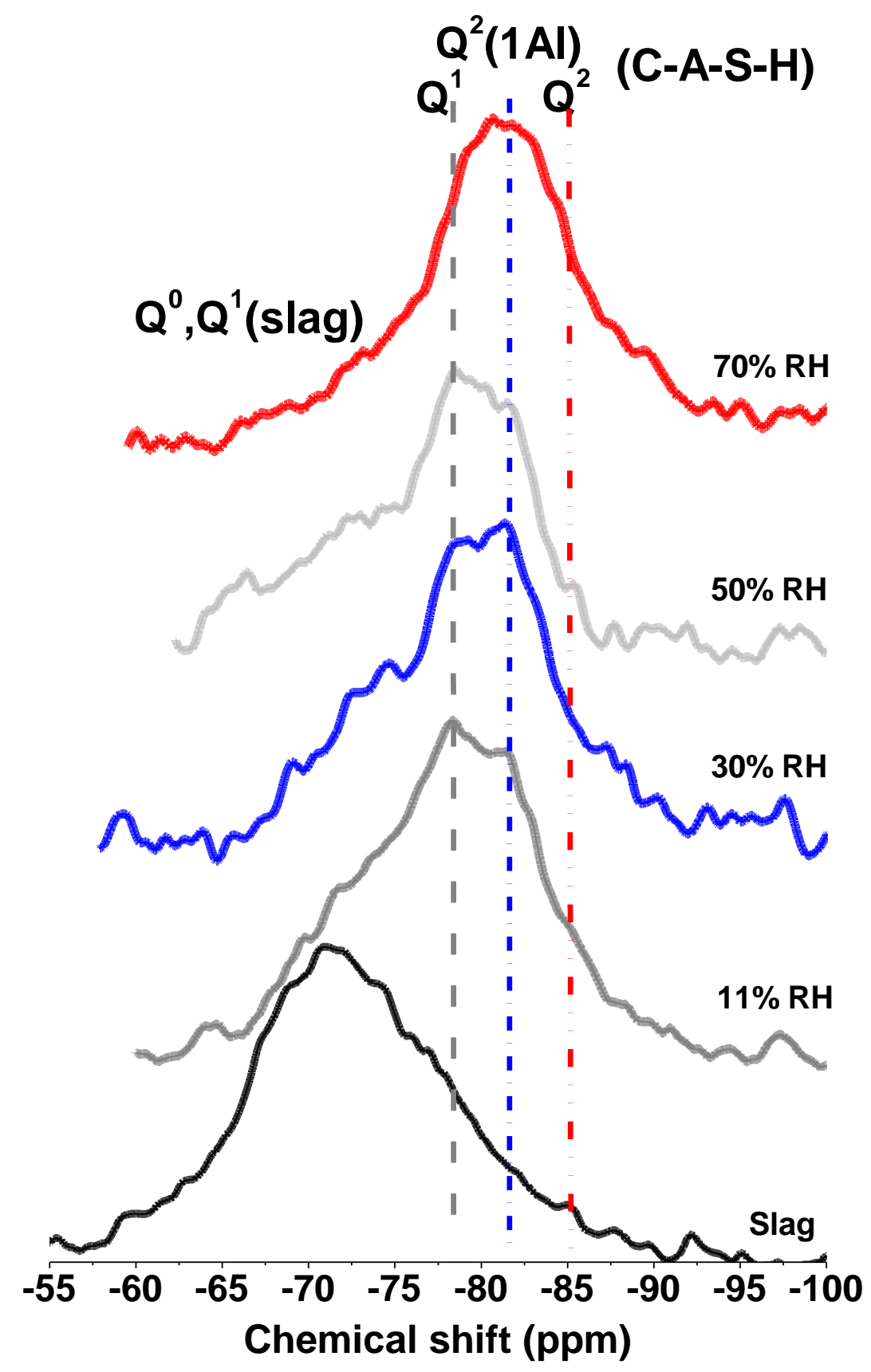

Figure $8{ }^{29} \mathrm{Si}$ solid-state NMR patterns of raw slag and AAS dried at various RH 


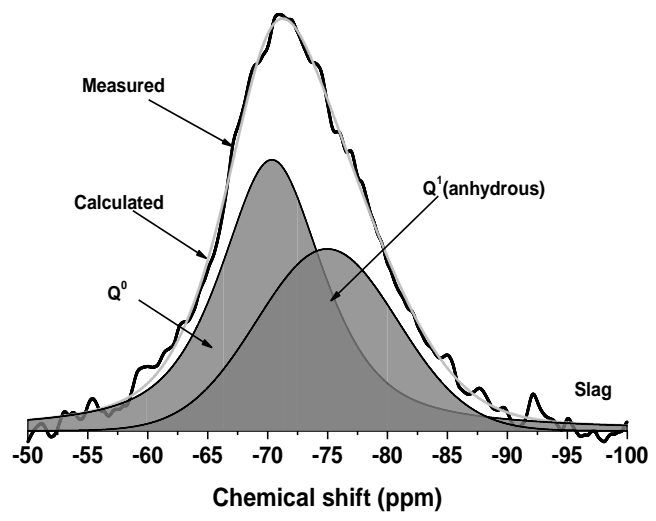

(a)

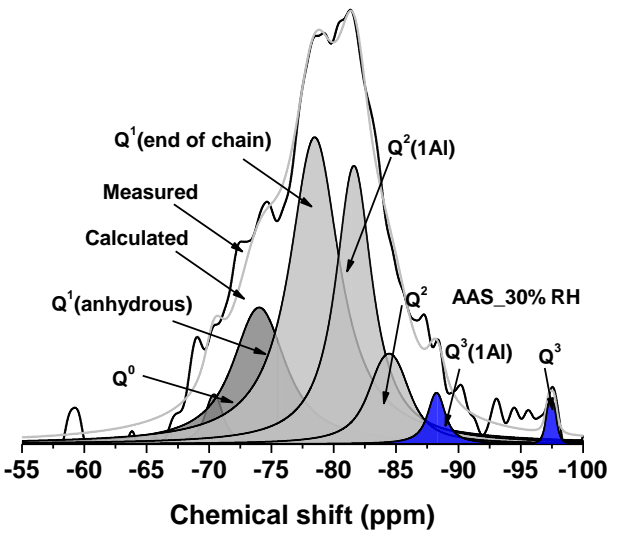

(c)

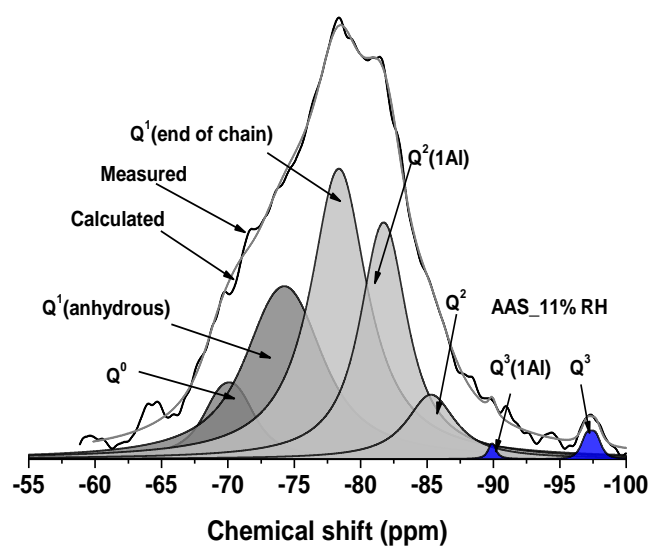

(b)

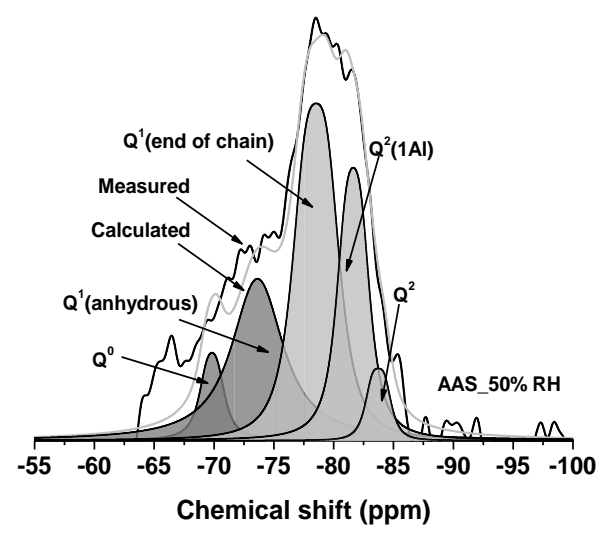

(d) 


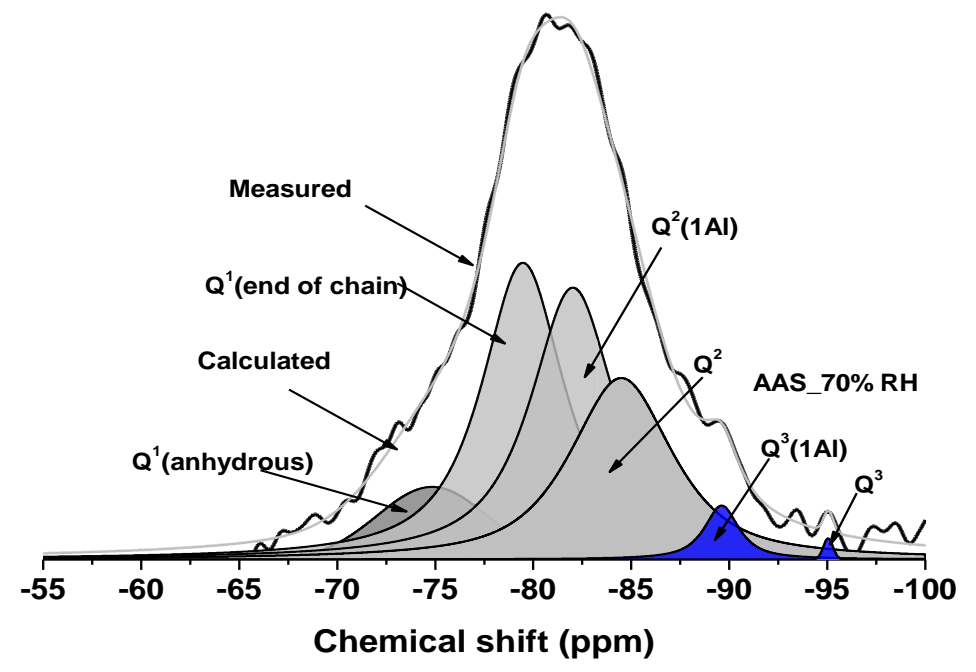

(e)

Figure 9 Deconvolution of ${ }^{29} \mathrm{Si}$ solid-state NMR patterns of raw slag and AAS dried at various RH (a) raw slag; (b)11\%RH; (c)30\%RH;(d)50\%RH; (e)70\%RH

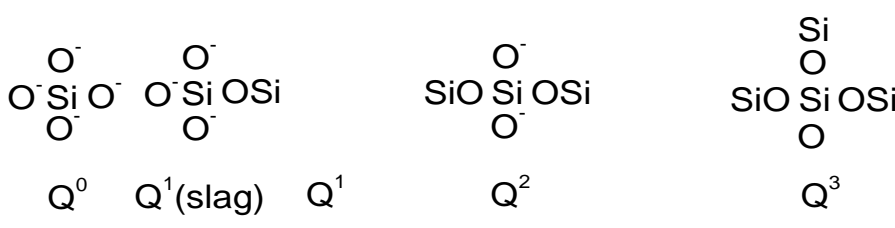

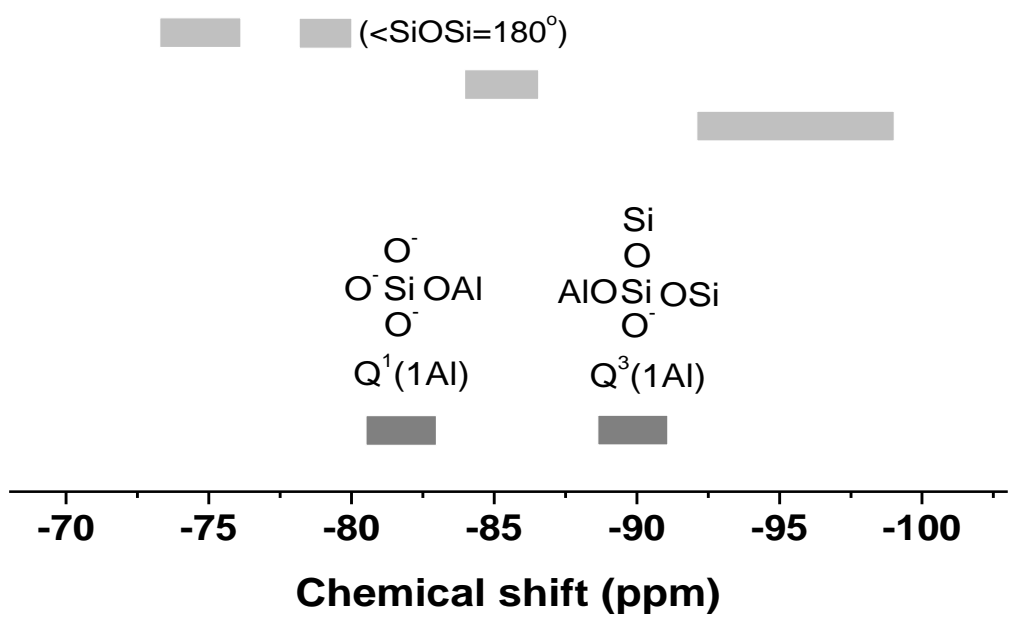


Figure 10 Range of chemical shift corresponding to $\mathrm{Q}^{\mathrm{n}}$ unit in silicates and $\mathrm{Q}^{\mathrm{n}}(1 \mathrm{Al})$ unit in aluminosilicate [27].

\section{Discussion}

\subsection{Shrinkage mechanism}

Given the considerable shrinkage (almost $20000 \mu \varepsilon$ ), the nature of C-A-S-H formed in AAS cannot be treated as a continuous porous material, but more likely as a gelled colloid or granular material with micro-defects [32] (see Figure 11 (a)). Considering the granular nature, the viscoelastic/visco-plastic shrinkage performance of AAS under drying can be attributed to the timedependent rearrangement and redistribution of C-A-S-H nanoparticles [32-34]. Therefore, the shrinkage of AAS at high $\mathrm{RH}(>50 \%)$ is basically a result of denser nanoparticle packing, which in principal will result in collapse of gel pores and refinement of pore structure (as reflected by the nitrogen and SEWVS isotherms data). In fact, as C-A-S-H nanoparticles are compacted under capillary pressure, partial initial large gel pores are re-constructed or translated into smaller pores. Therefore, some micropores closure seems to occur as drying continues, which generates some nitrogen inaccessible regions (see Figure $11(b)$ ). 
The C-A-S-H nanoparticle rearrangement is a permanent process and results in a primarily irreversible deformation in AAS. As supported by Figure 3, the AAS samples dried at $70 \%$ and 50\% RH show much slower and limited shrinkage/mass recoveries after soaked compared with those dried at $30 \%$ and $11 \%$ RH. As suggested by Feldman, most of irreversible shrinkage of OPC is achieved by drying from $100 \% \mathrm{RH}$ to $50 \% \mathrm{RH}[32,35]$. The primary reason is because at high $\mathrm{RH}$, the formation of stable capillary meniscus severs as the driving force for C-S-H nanoparticle rearrangement $[32,36]$. The well-known Kelvin-Laplace equation is commonly used to establish the correlation between relative humidity, capillary pressure, and radius of meniscus [37]:

$$
p_{c}=-\frac{2 \gamma \cdot \cos \theta}{r_{c}}=\rho_{l} \frac{R T}{M} \ln R H
$$

Where $p_{c}$ is the capillary pressure, $\rho_{l}$ is density of liquid, $M$ is molar mass of liquid, $R$ is the universal gas constant, $T$ is temperature in Kelvin, $r_{c}$ is capillary radius at the position of meniscus, also named Kelvin radius; $\gamma$ is surface tension between pore water and vapor, $\theta$ is the contact angle denoting the hydrophilicity of pore wall. As a consequence of Eq. (4), at a given $\mathrm{RH}$, all pores whose radii are smaller than Kelvin radius are completely filled with water, whereas larger pores have dried with layers of adsorbed water adhering to the pore wall [38, 39]. In addition, the capillary pressure is primarily controlled by the $\mathrm{RH}$ at equilibrium condition, irrespective of the pore size [40]. It should be noted that the liquid in capillary pores is under hydrostatically tensile stress condition, and can exert force to pull adjacent solids closer. 
According to the Kelvin-Laplace equation, at $70 \% \mathrm{RH}$, all pores with radii greater than about 5 $\mathrm{nm}$ are emptied. It indicates that all capillary pores and partial large gel pores are empty. While dried at lower $\mathrm{RH}(<50 \% \mathrm{RH})$, merely small gel and interlayer pores are likely to be statured. Therefore, the occurred C-A-S-H particle re-arrangement at $70 \% \mathrm{RH}$ is easier to be observed since $\mathrm{N}_{2}$ can access to the large gel pores but cannot access small gel pores and interlayer spaces [32].

According to previous research, $40 \% \mathrm{RH}$ (or $50 \% \mathrm{RH}$ ) is typically regarded as the critical $\mathrm{RH}$ in which the capillary meniscus becomes unstable at equilibrium condition, and air-water interface enters small gel pores $[32,36,39,41]$. Another shrinkage mechanism, mainly surface free energy, was reported to become dominating at low RH [41]. Different with capillary pressure, alteration of surface free energy results in a total different stress in direction, magnitude and location. The capillary stress is more likely to be a confining pressure which drives the adjacent solid particles closer, while surface free energy triggers the densification of particle itself [42]. At such, given that the meniscus is unstable for cementitious materials dried below $40 \%$ 50\% $\mathrm{RH}$, the shrinkage development of AAS at $30 \%$ and $11 \% \mathrm{RH}$ may not show as strong viscous characteristics as that dried at 50\% and 70\% RH (see Figure 1 (a)). In other words, the origin of observed viscous characteristics in AAS is attributed to the rearrangement and reorganization of C-A-S-H under capillary stress due to meniscus formation. However, temporal capillary meniscus is still able to form during the drying at $30 \%$ and $11 \% \mathrm{RH}$, because of the kinetics effects of drying [43]. Therefore, it is not surprising to observe (see Figures 1 (a) and 2) that the 
shrinkage development of AAS at $30 \%$ and $11 \%$ RH shows transient viscous characteristics at early days of drying, but then becomes almost stagnant.

In addition, the calculated BET-surface area of hydration products in AAS samples dried at $11 \% \mathrm{RH}$ is highest, probably because of the densification of C-A-S-H particles, which renders in a reduction in interlayer spacing (see XRD patterns) by removing interlayer water, as well as reopens some initial $\mathrm{N}_{2}$-inaccessible pores (see Figure 11 (c)).

Previous research indicated that the BET-surface area by nitrogen sorption tests reaches a local minimum value at around $40 \%$ to $50 \% \mathrm{RH}$ for OPC $[41,44]$. Parrott et al. attributed that to the closure of nitrogen-accessible pores by capillary tension stress [44]. However, the RH corresponding to that minimum surface area is likely to be higher in AAS than that of OPC. It indicates that there is a considerable amount of pores ranging from $2 \mathrm{~nm}-4 \mathrm{~nm}$ in AAS, which corresponds to the higher magnitude of shrinkage.

The C-A-S-H nanoparticles interact and rearrange inevitably results in some physical-chemical reactions, including micropore closure, Si polymerization, MCL enlargement, and interlayer structural reconstruction (see Figure 11 (b)). As evidenced by Figure 7, AAS dried at 70\%RH shows an increasing intensity of interlayer thickness reflection, which could indicate that there are new interlayers re-constructed during reorganization process. It may also suggest that C-A-S- 
$\mathrm{H}$ nanoparticles rearrange in a manner of inter-particle boundary sliding. On the other hand, as the $\mathrm{Al} / \mathrm{Si}$ ratio in $\mathrm{C}-\mathrm{A}-\mathrm{S}-\mathrm{H}$ gel is almost kept constant, the dramatic increase in the MCL indicates that some $\mathrm{Si}$ initially at the end chain of C-A-S-H ( $\mathrm{Q}^{1}$ environment) polymerize to form $\mathrm{Q}^{2}$. It confirms that this reaction very likely occurs between adjacent C-A-S-H sheets. The alkali cations that incorporates in the nanostructure of C-A-S-H or adsorbs at C-A-S-H surfaces, is likely to be responsible for this observation, as elaborated in Section 4.2.

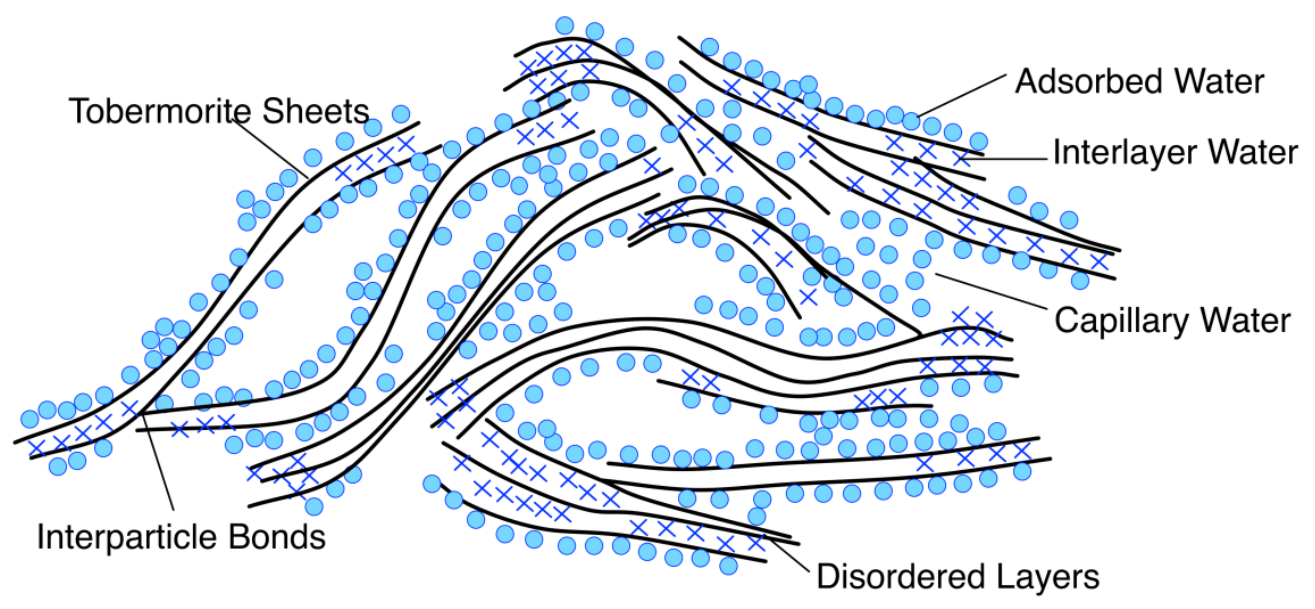

(a) 


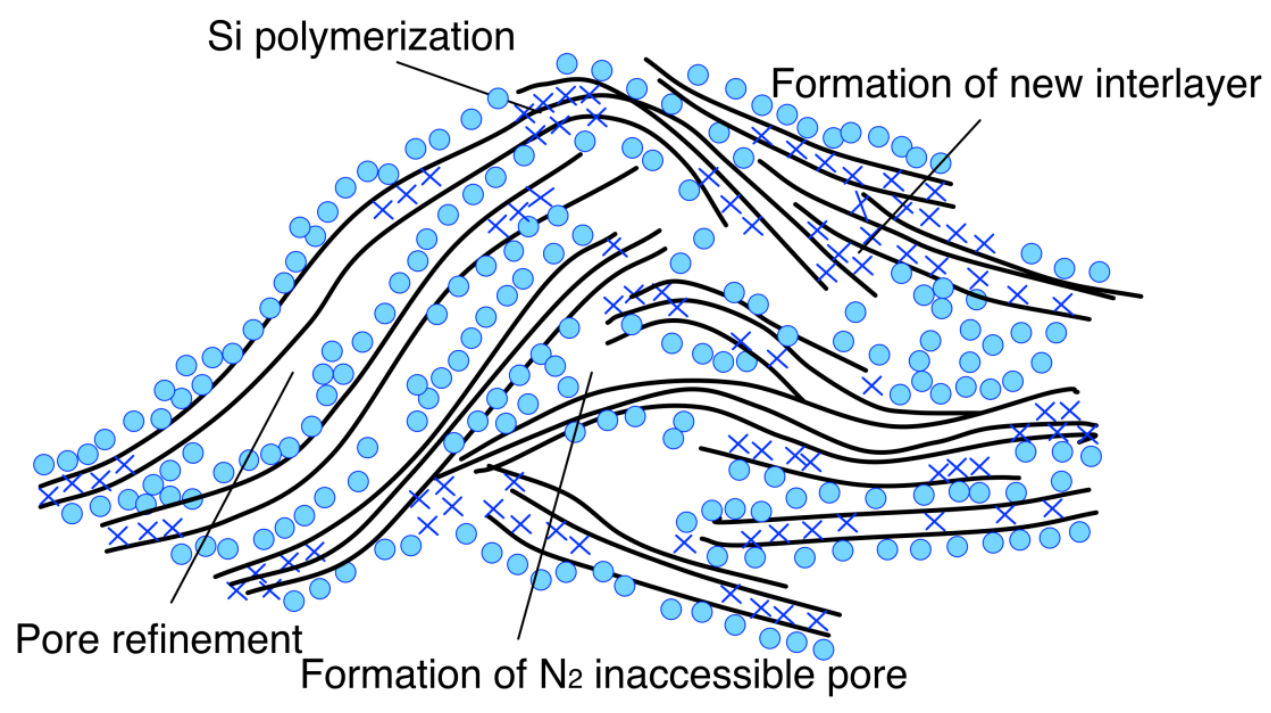

(b)

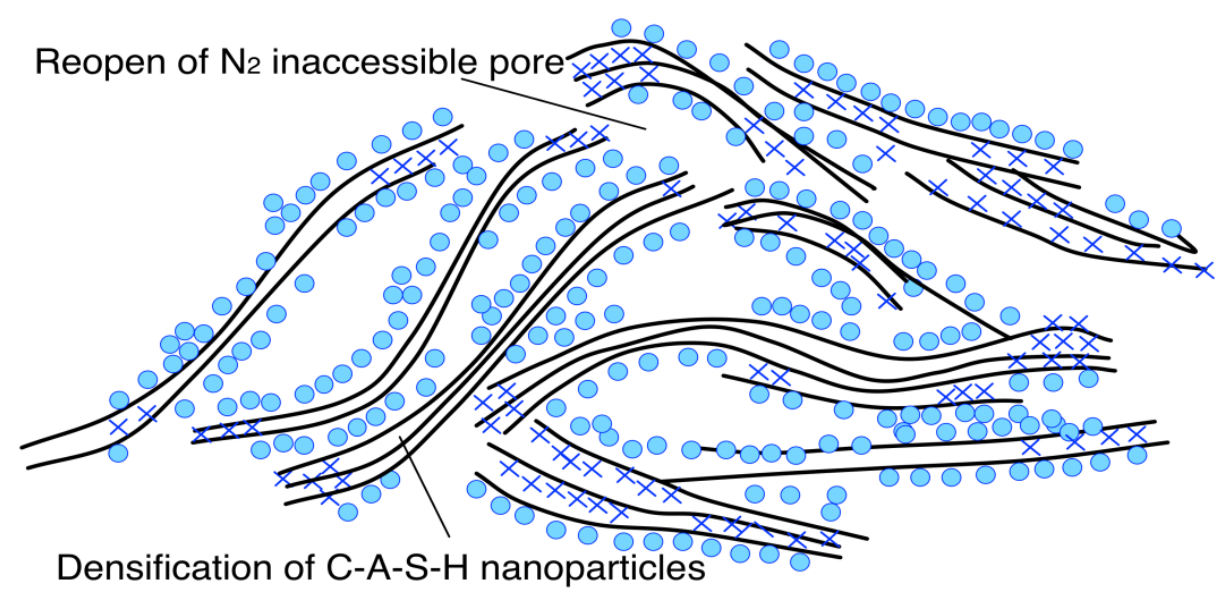

(c)

Figure 11 Illustration of nanostructure changes of C-A-S-H during drying (a) Before drying, CA-S-H comprises of primarily amorphous tobermorite-like sheets. (b) After drying, C-A-S-H redistributes and organizes; rendering pore refinement, silicate polymerization, and new interlayer formation (c) Dried at low RH ( 11\%RH), C-A-S-H densifies and loses some interlayer water. 
A pronounced visco-elastic/visco-plastic mechanical response of AAS upon drying, in comparison to OPC, is probably due to its distinct C-A-S-H nanostructure from that of C-S-H in OPC. The XRD pattern (Figure 7) shows that the C-S-H (I) formed in AAS is more crystalline than that C-S-H formed in OPC, since the peak corresponding to interlayer d-spacing $(\sim 12.5 \AA)$ cannot be observed in hydrated OPC. However, a recent study using synchrotron XRD reveals that the C-A-S-H in AAS only contains coherent atom-atom correlations up to $\sim 15 \AA$, which is much smaller than that in OPC (up to $\sim 40 \AA$ for hydrated C3S) [45]. It indicates that the atoms at the surface of C-A-S-H nanoparticles are more disorderedly arranged, likely promoting the sliding and gliding of C-A-S-H along inter-particle boundaries and contributing to the interaction of adjacent C-A-S-H particles.

According to a previous study regarding the influence of $1 \mathrm{M} \mathrm{NaOH}$ on the drying shrinkage of OPC pastes, it is recognized that $\mathrm{NaOH}$-containing OPC samples continue to shrink without losing moisture (i.e. viscous response) [46], which is analogous to the observation made on AAS investigated in this work. The alkali cation that is incorporated into the nanostructure of C-A-S$\mathrm{H}$ or adsorbed at surface of $\mathrm{C}-\mathrm{A}-\mathrm{S}-\mathrm{H}$ is very likely to be responsible for this viscous shrinkage performance for both AAS and OPC containing alkalis. It should be noted that differentiating the alkali binding sites either in the nanostructure (interlayer) or at the surface of $\mathrm{C}-\mathrm{A}-\mathrm{S}-\mathrm{H}$ is 
challenging via currently-available analytical techniques [47]. However, the incorporation of the alkalis into the C-A-S-H nanostructure or cluster seems to be significant and may provide at least a partial explanation for the findings that the C-A-S-H in AAS is structurally distinct from the C$\mathrm{S}-\mathrm{H}$ product of C3S hydration $[47,48]$. First, the presence of alkalis can increase the proportion of non-bridging oxygen in silicate structure (i.e. increase $\mathrm{Q}^{1}$ signal in ${ }^{29} \mathrm{Si} \mathrm{NMR}$ ) and terminate the silicate chain of C-A-S-H (i.e. reduce the mean chain length) [49]. These alkalis-terminated sites may serve as additional available locations (as a vacancy defects) for microstructure arrangement (e.g. $\equiv \mathrm{Si}-\mathrm{ONa}+\mathrm{HO}-\mathrm{Si} \equiv \rightarrow=\mathrm{Si}-\mathrm{O}-\mathrm{Si} \equiv+\mathrm{NaOH})$. Furthermore, the incorporation of alkali cations seems to reduce the regularity of the stacking of the C-A-S-H layers through differences in ionic size [49], and make the C-A-S-H easier to collapse and redistribute upon drying. This hypothesis is partially supported by the drying-induced physical-chemical changes in C-A-S-H observed in this study.

On the other hand, a lower stiffness of $\mathrm{NaOH}$-activated slag was reported as compared to OPC in previous work [4], which can increase the elastic deformation although it is insufficient to account for the viscous characteristics. In fact, due to its composite nature, the mechanical properties of cementitious materials are strongly associated with the dispersed inclusion (e.g. unhydrated particles, crystals) [50]. Previous calculations have shown that the existence of nanosized portlandite considerably increases the stiffness of OPC [51]. This can partially account for the lower stiffness and enlarged shrinkage in AAS, due to its limited amount of portlandite. 


\section{Conclusions}

In this paper, the physical and chemical changes of AAS dried at various RH conditions were studied, in order to explore the underlying shrinkage mechanisms. Following conclusions can be drawn according to this study:

(1) In comparison to OPC, AAS shows considerably high drying shrinkage and moisture loss, regardless of exposed RH. The shrinkage of AAS exhibits a pronounced viscous characteristic upon drying especially at high RH. In addition, the kinetics of shrinkage in AAS is strongly dependent on the experienced RH.

(2) The viscous performance in AAS is due to the rearrangement and reorganization of C-A-S-H particles (layered sheets) under the capillary stress. Therefore, most of the shrinkage in AAS dried at high $\mathrm{RH}$ is irreversible since reorganized structure is almost permanent.

(3) At $11 \% \mathrm{RH}$, removal of interlayer water is observed in AAS and may account for the shrinkage as well.

(4) During drying-induced microstructure rearrangement, considerable chemical (e.g. silicate polymerization, chain length elongation) and physical (e.g. micropore closure, interlayer formation and sliding) modifications occur in AAS. 
(5) The large shrinkage in AAS may be attributed to the structural incorporation of alkali cations in $\mathrm{C}-\mathrm{A}-\mathrm{S}-\mathrm{H}$, which reduces the stacking regularity of $\mathrm{C}-\mathrm{A}-\mathrm{S}-\mathrm{H}$ layers and make the C-A-S-H easier to collapse and redistribute upon drying.

\section{Acknowledgements}

The authors gratefully acknowledge the financial support from the U.S. National Science Foundation (NSF) under Award CMMI \#1265789. Any opinions, findings and conclusions or recommendations expressed in this material are those of the authors and do not necessarily reflect the views of the NSF.

\section{References}

[1] R.J. Thomas, H. Ye, A. Radlińska, S. Peethamparan, Alkali-activated slag concrete: A closer look at sustainable alternatives to portland cement, Concrete International, 38 (2016) 33-38.

[2] M. Juenger, F. Winnefeld, J. Provis, J. Ideker, Advances in alternative cementitious binders, Cement and Concrete Research, 41 (2011) 1232-1243.

[3] M. Jiang, X. Chen, F. Rajabipour, C.T. Hendrickson, Comparative Life Cycle Assessment of Conventional, Glass Powder, and Alkali-Activated Slag Concrete and Mortar, Journal of Infrastructure Systems, 20 (2014).

[4] C. Cartwright, F. Rajabipour, A. Radlińska, Shrinkage characteristics of alkali-activated slag cements, Journal of Materials in Civil Engineering, (2014) B4014007. 
[5] H. Ye, C. Cartwright, F. Rajabipour, A. Radlińska, Effect of drying rate on shrinkage of alkali-activated slag cements, 4th International Conference on the Durability of Concrete Structure (ICDCS)Purdue University, Indiana, USA, 2014, pp. 254-261.

[6] T. Bakharev, J. Sanjayan, Y.-B. Cheng, Resistance of alkali-activated slag concrete to carbonation, Cement and Concrete Research, 31 (2001) 1277-1283.

[7] S.-D. Wang, X.-C. Pu, K. Scrivener, P. Pratt, Alkali-activated slag cement and concrete: a review of properties and problems, Advances in cement research, 7 (1995) 93-102.

[8] F. Collins, J. Sanjayan, Effect of pore size distribution on drying shrinking of alkali-activated slag concrete, Cement and Concrete Research, 30 (2000) 1401-1406.

[9] A.A. Melo Neto, M.A. Cincotto, W. Repette, Drying and autogenous shrinkage of pastes and mortars with activated slag cement, Cement and Concrete Research, 38 (2008) 565-574.

[10] C. Duran Atiş, C. Bilim, Ö. Çelik, O. Karahan, Influence of activator on the strength and drying shrinkage of alkali-activated slag mortar, Construction and building materials, 23 (2009) 548-555.

[11] J. Zhang, G.W. Scherer, Comparison of methods for arresting hydration of cement, Cement and Concrete Research, 41 (2011) 1024-1036.

[12] K.L. Scrivener, Backscattered electron imaging of cementitious microstructures: understanding and quantification, Cement and Concrete Composites, 26 (2004) 935-945.

[13] S. Brunauer, P.H. Emmett, E. Teller, Adsorption of gases in multimolecular layers, Journal of the American Chemical Society, 60 (1938) 309-319.

[14] J. Weiss, P. Lura, F. Rajabipour, G. Sant, Performance of shrinkage-reducing admixtures at different humidities and at early ages, ACI Materials Journal, 105 (2008). 
[15] W. Hansen, Drying shrinkage mechanisms in Portland cement paste, Journal of the American Ceramic society, 70 (1987) 323-328.

[16] M.B. Haha, G. Le Saout, F. Winnefeld, B. Lothenbach, Influence of activator type on hydration kinetics, hydrate assemblage and microstructural development of alkali activated blastfurnace slags, Cement and Concrete Research, 41 (2011) 301-310.

[17] B.S. Gebregziabiher, R. Thomas, S. Peethamparan, Very early-age reaction kinetics and microstructural development in alkali-activated slag, Cement and Concrete Composites, 55 (2015) 91-102.

[18] D. Hobbs, Influence of aggregate restraint on the shrinkage of concrete, ACI J, 71 (1974) 445-450.

[19] J. Rouquerol, F. Rouquerol, P. Llewellyn, G. Maurin, K.S. Sing, Adsorption by powders and porous solids: principles, methodology and applications, Academic press2013.

[20] K.K. Aligizaki, Pore structure of cement-based materials: testing, interpretation and requirements, CRC Press2005.

[21] I. Ismail, S.A. Bernal, J.L. Provis, S. Hamdan, J.S. van Deventer, Drying-induced changes in the structure of alkali-activated pastes, Journal of Materials Science, 48 (2013) 3566-3577.

[22] H. Ranaivomanana, J. Verdier, A. Sellier, X. Bourbon, Toward a better comprehension and modeling of hysteresis cycles in the water sorption-desorption process for cement based materials, Cement and Concrete Research, 41 (2011) 817-827.

[23] R.S. Mikhail, L.E. Copeland, S. Brunauer, Pore structures and surface areas of hardened Portland cement pastes by nitrogen adsorption, Canadian Journal of Chemistry, 42 (1964) 426438. 
[24] N. De Belie, J. Kratky, S. Van Vlierberghe, Influence of pozzolans and slag on the microstructure of partially carbonated cement paste by means of water vapour and nitrogen sorption experiments and BET calculations, Cement and Concrete Research, 40 (2010) 17231733.

[25] S.-D. Wang, K.L. Scrivener, Hydration products of alkali activated slag cement, Cement and Concrete Research, 25 (1995) 561-571.

[26] H. Ye, A. Radlińska, Quantitative analysis of phase assemblage and chemical shrinkage of alkali-activated slag, Journal of Advanced Concrete Technology, 14 (2016) 245-260.

[27] G. Engelhardt, D. Michel, High-resolution solid-state NMR of silicates and zeolites, (1987).

[28] G. Renaudin, J. Russias, F. Leroux, C. Cau-dit-Coumes, F. Frizon, Structural characterization of $\mathrm{C}-\mathrm{S}-\mathrm{H}$ and $\mathrm{C}-\mathrm{A}-\mathrm{S}-\mathrm{H}$ samples - Part II: Local environment investigated by spectroscopic analyses, Journal of Solid State Chemistry, 182 (2009) 3320-3329.

[29] I.G. Richardson, A.R. Brough, R. Brydson, G.W. Groves, C.M. Dobson, Location of aluminum in substituted calcium silicate hydrate $(\mathrm{C}-\mathrm{S}-\mathrm{H})$ gels as determined by 29Si and 27Al NMR and EELS, Journal of the American Ceramic Society, 76 (1993) 2285-2288.

[30] I. Richardson, G. Groves, The structure of the calcium silicate hydrate phases present in hardened pastes of white Portland cement/blast-furnace slag blends, Journal of Materials Science, 32 (1997) 4793-4802.

[31] J. Skibsted, M.D. Andersen, The effect of alkali ions on the incorporation of aluminum in the calcium silicate hydrate $(\mathrm{C}-\mathrm{S}-\mathrm{H})$ phase resulting from Portland cement hydration studied by 29Si MAS NMR, Journal of the American Ceramic Society, 96 (2013) 651-656.

[32] H.M. Jennings, Refinements to colloid model of CSH in cement: CM-II, Cement and Concrete Research, 38 (2008) 275-289. 
[33] H. Ye, Creep Mechanisms of Calcium-Silicate-Hydrate: An Overview of Recent Advances and Challenges, International Journal of Concrete Structures and Materials, 9 (2015) 453-462.

[34] M. Vandamme, F.-J. Ulm, Nanogranular origin of concrete creep, Proceedings of the National Academy of Sciences, 106 (2009) 10552-10557.

[35] R.F. Feldman, P.J. Sereda, A model for hydrated Portland cement paste as deduced from sorption-length change and mechanical properties, Matériaux et Construction, 1 (1968) 509-520. [36] H.M. Jennings, Colloid model of $\mathrm{C}-\mathrm{S}-\mathrm{H}$ and implications to the problem of creep and shrinkage, Materials and structures, 37 (2004) 59-70.

[37] A.W. Adamson, A.P. Gast, Physical chemistry of surfaces, (1967).

[38] A. Radlinska, F. Rajabipour, B. Bucher, R. Henkensiefken, G. Sant, J. Weiss, Shrinkage mitigation strategies in cementitious systems: A closer look at differences in sealed and unsealed behavior, Transportation Research Record: Journal of the Transportation Research Board, (2008) $59-67$.

[39] H. Ye, A. Radlińska, A review and comparative study of existing shrinkage prediction models for portland and non-portland cementitious materials Advances in Materials Science and Engineering, 2016 (2016) Article ID: 2418219.

[40] J. Mackenzie, The elastic constants of a solid containing spherical holes, Proceedings of the Physical Society. Section B, 63 (1950) 2.

[41] I. Maruyama, Y. Nishioka, G. Igarashi, K. Matsui, Microstructural and bulk property changes in hardened cement paste during the first drying process, Cement and Concrete Research, 58 (2014) 20-34.

[42] K. Kovler, S. Zhutovsky, Overview and future trends of shrinkage research, Materials and Structures, 39 (2006) 827-847. 
[43] G.W. Scherer, Theory of drying, Journal of the American Ceramic Society, 73 (1990) 3-14.

[44] L. Parrott, W. Hansen, R. Berger, Effect of first drying upon the pore structure of hydrated alite paste, Cement and Concrete Research, 10 (1980) 647-655.

[45] C.E. White, L.L. Daemen, M. Hartl, K. Page, Intrinsic differences in atomic ordering of calcium (alumino) silicate hydrates in conventional and alkali-activated cements, Cement and Concrete Research, 67 (2015) 66-73.

[46] M.C.G. Juenger, H.M. Jennings, Effects of high alkalinity on cement pastes, ACI Materials Journal, 98 (2001).

[47] J.L. Provis, A. Palomo, C. Shi, Advances in understanding alkali-activated materials, Cement and Concrete Research, 78 (2015) 110-125.

[48] R.J. Myers, S.A. Bernal, J.L. Provis, A thermodynamic model for C-(N-) ASH gel: CNASH_ss. Derivation and validation, Cement and Concrete Research, 66 (2014) 27-47.

[49] B. Lothenbach, A. Nonat, Calcium silicate hydrates: Solid and liquid phase composition, Cement and Concrete Research, 78 (2015) 57-70.

[50] D.J. Green, An introduction to the mechanical properties of ceramics, Cambridge University Press 1998.

[51] J.J. Chen, L. Sorelli, M. Vandamme, F.J. Ulm, G. Chanvillard, A Coupled Nanoindentation/SEM-EDS Study on Low Water/Cement Ratio Portland Cement Paste: Evidence for $\mathrm{C}-\mathrm{S}-\mathrm{H} / \mathrm{Ca}(\mathrm{OH}) 2$ Nanocomposites, Journal of the American Ceramic Society, 93 (2010) 1484-1493. 